\title{
Understanding the behaviour of graphene oxide in Portland cement paste
}

\author{
Sam Ghazizadeh ${ }^{\mathrm{a}, *}$, Philippe Duffour ${ }^{\mathrm{a}}$, Neal T. Skipper ${ }^{\mathrm{b}}$, Yun Bai ${ }^{\mathrm{a}}$ \\ ${ }^{a}$ University College London, Department of Civil, Environmental $\& 3$ Geomatic Engineering, \\ London, WC1E 6BT, United Kingdom \\ ${ }^{b}$ University College London, London Centre for Nanotechnology, Department of Physics \\ and Astronomy, London, WC1E 6BT, United Kingdom
}

\begin{abstract}
This study reports on the effect of graphene oxide (GO) on the hydration of Portland cement (PC) and industrial clinker. GO accelerates PC hydration, whereas it temporarily retards that of clinker. This difference reflects a twofold behaviour of GO in cement pastes. Retardation is due to the interaction of GO with the surface of hydrating grains, while acceleration results from a seeding effect. Gypsum causes this difference. GO is shown to have little effect on the strength of hardened pastes, and this merely relates to the change of hydration degree, as opposed to reinforcing effect formerly assumed. Overall, GO is not particularly active as a nucleation surface, as it aggregates and behaves in a similar way to inert fillers (e.g. quartz). Polycarboxylate-ether copolymer could make GO an active seed in cement pastes, as it prevents GO from aggregating. Nevertheless, this was found to occur only in alite pastes but not PC pastes.

Keywords: Graphene oxide, Portland cement, Alite, Polycarboxylate-ether copolymer, Hydration kinetics
\end{abstract}

\section{Introduction}

2 Graphene oxide (GO) is composed of a single layer of mixed $\mathrm{sp}^{2}$ and $\mathrm{sp}^{3}$ hy3 bridised carbon atoms, functionalised with various oxygen-derived groups such

\footnotetext{
* Corresponding author

Email address: s.ghazizadeh@ucl.ac.uk (Sam Ghazizadeh)
}

Preprint submitted to Cement and Concrete Research

May 30, 2018 
4 as carbonyl, hydroxyl and carboxyl [1]. A GO single layer has a thickness of 5 about $0.7-1 \mathrm{~nm}$ and a lateral size ranging from hundreds of nanometers to tens or hundreds of micrometers [2]. Fig. 1 shows a schematic model of GO molecular structure. It is generally accepted that carboxyl sites are primarily located around the edges of GO layers whereas the other functional groups are within the carbon network $[1,2]$. These oxygen groups are hydrophilic, which allows GO to form stable colloids in water. As a derivative of graphene, GO possesses a high in-plane Young's modulus (210 to $470 \mathrm{GPa}[3,4])$ and high specific surface area $\left(1500-1700 \mathrm{~m}^{2} / \mathrm{g}[5,6]\right)$. Due to these characteristics, it has often been stated that GO could be utilised as a reinforcing and/or nucleation-seeding additive in cement pastes whose matrix suffers from a low tensile strength $[7,8]$. Previous studies have claimed that adding GO to cement pastes or mortars improves the compressive, flexural and tensile strengths of these systems. The strength improvements were found to occur in systems made of Portland cement (PC) [7, 9-20], alkali activated slag [21] and magnesium phosphate [22]. The majority of these studies assumed that GO layers were well dispersed in the paste matrix. However, evidence has emerged that GO aggregates in the pore solution of alite [5] and PC pastes [23, 24]. Therefore, it seems likely that the strength improvements reported for PC-GO systems resulted from the presence of GO aggregates and not of single layers [25, 26].

GO is susceptible of aggregation in PC pastes, as it reacts with divalent and trivalent cations as well as hydroxide ions present in the paste solution. The aggregation occurs while mixing the paste, and starts from the very beginning of hydration when cement particles dissolve in water. The high $\mathrm{pH}$ level in PC pastes $(\mathrm{pH}>12)$ causes hydrogen to dissociate from the GO carboxyl sites where calcium, the most abundant cation in $\mathrm{PC}$ paste, forms $\mathrm{COO}^{-} \mathrm{Ca}^{2+}$ - OOC complexes [5]. Since calcium is a divalent cation, it tends to react with two carboxylated sites. As a result, it bridges the GO layers, causing their aggregation $[5,28]$. Other divalent or trivalent cations can act similarly [28, 29].

In addition to the cationic effect, GO reacts with hydroxide ions in alkaline solutions and loses the majority of its oxygen-bearing groups. Reduction of GO 


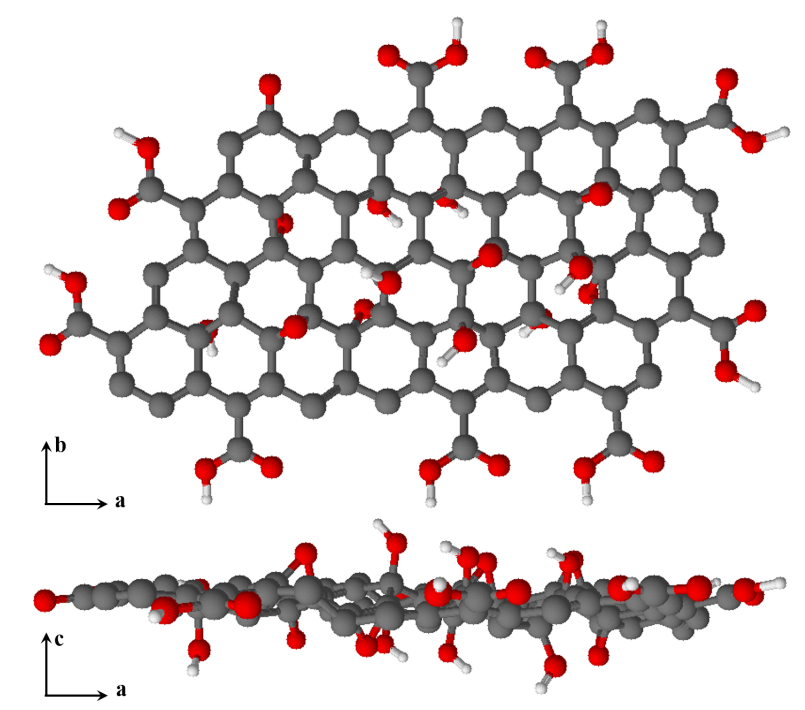

Fig. 1: A simple schematic model of GO atomic structure, showing the presence of carboxyl sites at edges of the GO layer while other functional groups, such as hydroxyl, are located on the basal plane. Grey, red and white atoms represent carbon, oxygen, and hydrogen, respectively. The actual atomic structure of GO is complicated and the oxygen groups are randomly distributed within the carbon network [1]. Compared to graphene, the structure of GO is damaged as a result of oxidation, with holes up to $5 \mathrm{~nm}^{2}$ present in some cases [27].

was found to occur in aqueous electrolytes containing $\mathrm{LiOH}$ [29], $\mathrm{NaOH}, \mathrm{KOH}$ $[30,31]$ and $\mathrm{Ca}(\mathrm{OH})_{2}[5]$. It appears that all GO functional groups are prone to reduction in alkaline solutions except carboxylate [31]. This phenomenon contributes to GO aggregation in alkaline solutions. GO remains dispersed in water because the oxygen groups on its basal plane increase the repulsive forces between the individual layers, overcoming the van der Waals attractions [28, 29].

However, as the oxygen groups disappear in alkaline solutions, the overall force acting between the GO layers switches from repulsion to attraction, causing GO to aggregate. Therefore, high $\mathrm{pH}$ environments, such as that of PC pore solution, tend to cause GO to aggregate [5].

Despite some of the recent advances in understanding the role of GO in PC pastes, several issues remain open. The first issue concerns the interaction of GO with cement particles while mixing the paste. GO is negatively charged in water (with zeta-potential lower than $-30 \mathrm{mV}$ ) as it carboxylates. GO layers become 
even more negatively charged in alkaline solutions, as more carboxyl sites are deprotonated [32]. Wang et al. [33] suggested that carboxylated GO adsorbs onto the surface of PC particles in the paste. This mechanism is plausible because $\mathrm{PC}$ grains are known to possess a positive electrostatic charge in water [34], so in principle, GO layers could be attracted to PC surfaces. This is similar to how carboxylated molecules or copolymers behave in cement pastes, where they are well known to retard cement hydration. They do this because they adsorb on the surface of hydrating particles and hinder the dissolution of cement and/or precipitation of hydration products [34-37]. However, this may not be the case for GO as it has been shown to accelerate cement hydration [5, 38]. Therefore, the charge characteristics of the surfaces alone seems insufficient to explain the interaction between GO and PC grains in water.

Secondly, the reason why GO strengthens PC pastes has remained unclear. Some suggest that GO serves for the nucleation of hydration precipitates, causing a higher degree of hydration $[9,10,12,14,16]$. Others propose that GO reinforces the paste matrix at the nano-scale $[11,15,17,18,20,25,26]$. A combination of these two mechanisms has also been suggested [7, 11, 15, 19, 38]. However, the reinforcing mechanism is often posited with no convincing evidence. Moreover, pastes containing GO hydrate faster than plain pastes, and this makes it difficult to decouple the effect of nucleation seeding from that of reinforcing.

Another issue relates to the methods proposed to prevent GO aggregation in PC paste pore solution $[23,24,39,40]$. Evidence exists that polycarboxylate ether (PCE) copolymer prevents GO from aggregation in $\mathrm{Ca}(\mathrm{OH})_{2}$ and $\mathrm{NaOH}$ electrolytes (molarities and PCE/GO ratios were unfortunately not specified) $[23,24]$. Lu et al. [39] demonstrated that PCE stabilises GO dispersion in dilute PC suspensions, with water-to-PC mass ratio of 15 . From this observation, they claim that $\mathrm{PCE}$ disperses $\mathrm{GO}$ in $\mathrm{PC}$ pastes with water-to-PC ratio of 0.35 , thereby strengthening the hardened matrix. Similar claims have also been reported elsewhere $[23,24,39]$. However, it is not obvious to which extent the behaviour of GO in such dilute suspensions can be generalised to pastes with 
much lower water content.

Following from our previous study on the effect of GO on alite hydration [5], a series of isothermal calorimetry tests were used in this paper to investigate the effect of GO on the hydration of industrial clinker, either alone or in substitution with gypsum and limestone. These systems were chosen because they are of intermediate complexity between alite and PC. The heat evolution patterns of clinker hydration are then compared to those obtained for alite and PC hydration. Results show that GO acts very differently in clinker paste compared to alite and PC pastes, which sheds some new light on the behaviour of GO in cement pastes. We also report the compressive strengths of $\mathrm{PC}$ and clinker pastes at 7,14 , and 28 days of hydration as a function of total hydration heat. This allows any reinforcing effect to be isolated from that of nucleation-seeding. Finally, this study reports on the effectiveness of PCE copolymer in dispersing GO nano-layers in alite or PC pastes, with a view to test some of the claims found in the literature.

\section{Materials and Methods}

\subsection{Synthesis and characterisation of graphene oxide}

Graphene oxide was synthesised following the procedure described in [5]. Three grams of graphite flakes (+100 mesh, Sigma Aldrich) were added to $360 \mathrm{~mL}$ of concentrated $\mathrm{H}_{2} \mathrm{SO}_{4}$ ( $\geq 95$ wt.\%, Fischer Chemicals) and $40 \mathrm{~mL}$ of concentrated $\mathrm{H}_{3} \mathrm{PO}_{4}$ ( $\geq 95$ wt.\%, Fischer Chemicals). Following this, $18 \mathrm{~g}$ of $\mathrm{KMnO}_{4}(\geq 99.0 \%$, Fluke Biochemika) was gradually added into the acidgraphite mixture. This mixture was kept at $25^{\circ} \mathrm{C}$ and left to stir for 96 hours using a magnetic stirrer. Thereafter, the mixture was cooled in an ice bath and was slowly diluted with $400 \mathrm{~mL}$ of distilled water. $\mathrm{H}_{2} \mathrm{O}_{2}$ solution $(\geq 30$ wt\%, Sigma Aldrich) was then added drop-wise to the reaction mixture until the solution became bright yellow and no further colour change was observed. The solids were collected by centrifugation at $3500 \mathrm{rpm}$ for 1 hour and were sequentially washed with deionised water, $\mathrm{HCl}(\sim 3.5$ wt.\%) and acetone (each 
conducted five times). The solid residue, which is graphite oxide, was dried for seven days under vacuum at room temperature.

Dried graphite oxide was characterised using an X-ray photoelectron spectrometer (K-Alpha XPS, ThermoFisher Scientific) with a monochromated Al $\mathrm{K}_{\alpha}$ source $(\mathrm{E}=1486.6 \mathrm{eV})$. The XPS spectra were recorded on dried graphite oxide flakes over a spot size of $400 \mu \mathrm{m}$ and dwell time of $50 \mathrm{~ms}$. The flakes were prepared by depositing the acetone-washed graphite oxide on a filter paper and drying it for seven days in a desiccator. This helped produce flakes with analogous thicknesses for XPS analyses (always $\sim 0.5 \mathrm{~mm}$ ). XPS survey scans (Fig. 2a) were conducted three times with a resolution of $1 \mathrm{eV}$, and the C1s spectrum (Fig. 2b) was recorded 10 times with a resolution of $0.1 \mathrm{eV}$. This setup was chosen based on a number of preliminary trials. Data shown in Fig. 2 confirm that the synthesised graphite oxide is mainly composed of carbon and oxygen (and hydrogen) with no other elements present in the sample, and that the synthesis procedure employed in this study resulted in a highly oxidised GO with oxygen-to-carbon ratio of about 0.52 . This was also consistent with the mass of the bulk graphite oxide after its synthesis; 3 grams of graphite led to about 5 grams of graphite oxide. The high oxidation level acquired in this study is in agreement with previous reports [41]. It is important to note that XPS surveys are often obtained on solid samples pressed onto a carbon substrate, but, as Fig. 2 shows, this gives an inaccurate elemental composition for graphite oxide as the carbon in the substrate could contribute to the XPS measurements. Indium was used on top of the carbon substrate in this study to avoid any background contribution from the substrate. Fig. $2 \mathrm{~b}$ shows the C1s pattern of graphite oxide, which confirms three chemical states for carbon consistent with our previous study [5]. In detail, these states relate to $\mathrm{sp}^{2}$ and $\mathrm{sp}^{3}$ hybridised, $\mathrm{C}=\mathrm{O}$ and $\mathrm{C}-\mathrm{O}$, and carboxyl-like structures.

GO colloids were prepared by exfoliating graphite oxide in de-ionised water using a sonication bath (Fisher Scientific, FB15050) for 1 hour. The thickness of GO layers was measured using the tapping mode of an Atomic Force Microscope (Bruker Dimension 3100). This technique is a typical way of characterising the 

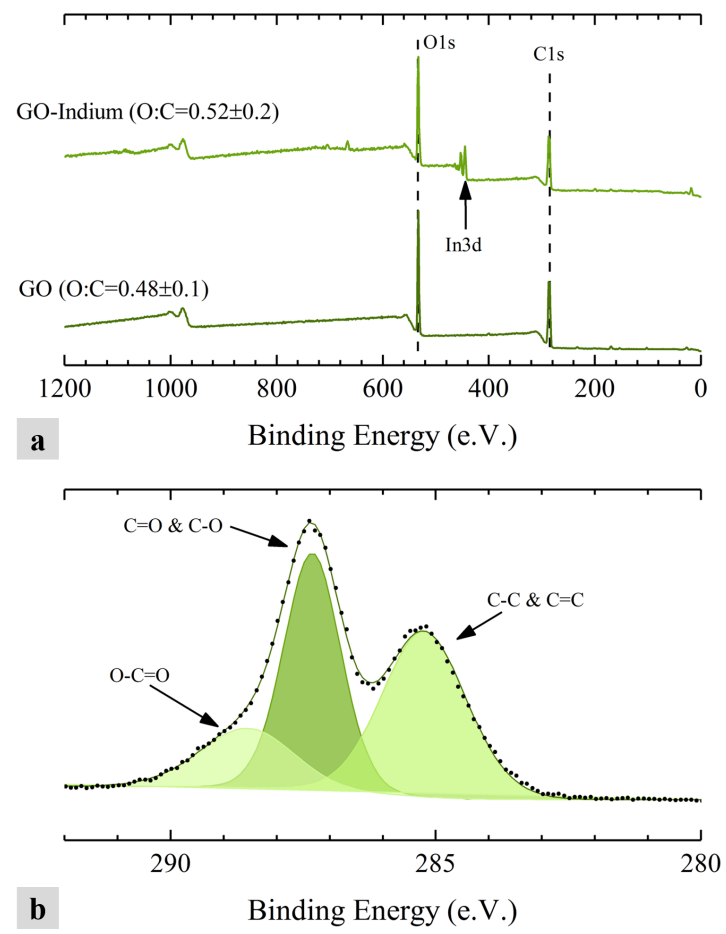

Fig. 2: XPS characterisation of graphite oxide. (a) XPS survey spectra of graphite oxide, recorded on samples that were pressed onto indium (top) or carbon (bottom) substrate. Data indicate an O:C ratio of 0.52 for sample on indium substrate, which is higher than that measured for the carbon substrate. This suggests that carbon substrate contributes to the XPS data and that data obtained on indium would give a better estimate of O:C ratio. Data also shows that the graphite oxide sample is mainly made of carbon and oxygen, and there is no trace of other elements in the sample. (b) C1s spectrum, suggesting three states for carbon: $\mathrm{sp}^{2}$ and $\mathrm{sp}^{3}$ hybridised, $\mathrm{C}=\mathrm{O}$ and $\mathrm{C}-\mathrm{O}$, and carboxyl-like structures.

thickness/topography of a GO sample [2]. The sample for AFM analysis was prepared by depositing a $0.5 \mathrm{mg} / \mathrm{ml}$ GO colloid on the surface of a freshly cleaved Mica surface. Mica was used because of its ultra-flat surface, providing a desired substrate for imaging GO layers. Fig. 3a shows the topographic image of deposited GO. The height profile of some of the layers are presented in Fig. 3b. As it can be seen, GO is mostly in the form of single layers with a thickness of about $1 \mathrm{~nm}$, consistent with our previous work [5]. The oxidation method used in this study resulted in a graphite oxide that readily exfoliates in water with 
no need to add any other chemicals, such as surfactants [5].

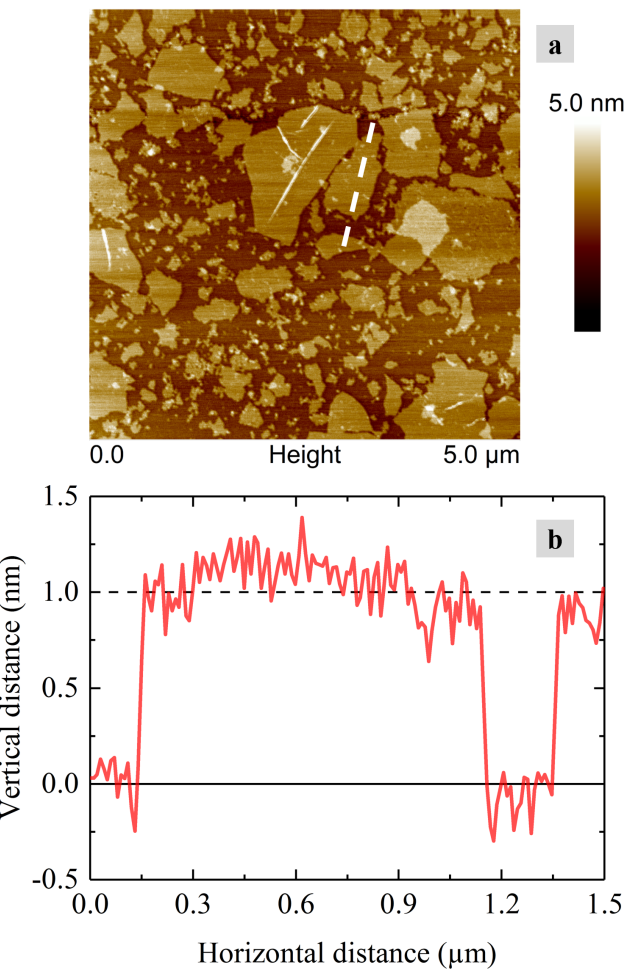

Fig. 3: AFM micrograph of GO single layers. (a) tapping mode image of GO deposited on the mica surface, (b) height profile for the dashed-line shown in figure (a). GO has a thickness of about $1 \mathrm{~nm}$, consistent with previous observations [5, 41]. This thickness was dominant in the sample.

\subsection{Inorganic materials}

Three hydraulic materials were used in this study: PC, industrial clinker and alite. PC and clinker were both supplied by Quinn building products (UK). PC was CEM I 52.5N in accordance with the composition specified in British standard [42]. Clinker was received in the form of large aggregates which were ground using a ball-mill grinder (PM 100, Retsch), and particles passed through a $80 \mu \mathrm{m}$ sieve were used. After grinding the clinker, the powders were stored in a well-sealed container to avoid contact with the moisture present in laboratory environment. Alite, which is a mono-clinic polymorph of $\mathrm{Ca}_{3} \mathrm{SiO}_{5}\left(\mathrm{C}_{3} \mathrm{~S}\right)$, 
was synthesised in the laboratory according to the high-temperature solid-state procedure followed in [5]. A 3:1 stoichiometric mixture of high-purity $\mathrm{CaCO}_{3}$ and $\mathrm{SiO}_{2}$ ( $\geq 99$ wt.\%, Sigma Aldrich) doped by 1.1 wt.\% MgO and 0.7 wt.\% $\mathrm{Al}_{2} \mathrm{O}_{3}$ ( $\geq 99$ wt.\%, Sigma Aldrich) were blended and wet-homogenised in a mixer. Following this, the mixture was dried and de-carbonated for 5 hours at $1000{ }^{\circ} \mathrm{C}$. The resultant product was pressed into pellets and heated at 1500 ${ }^{\circ} \mathrm{C}$ for a period of 8 hours in a muffle furnace. Sintering was repeated three times to reduce the amount of free calcium oxide remaining in the sample [43]. The pellets were then removed from the furnace and quenched immediately in the air. Once cooled, the material was ground using the ball-mill grinder, and particles passed the $80 \mu \mathrm{m}$ sieve were selected for this study.

Gypsum $\left(\mathrm{CaSO}_{4} \cdot 2 \mathrm{H}_{2} \mathrm{O}\right)$ and limestone powders were obtained from SaintGobain (UK) and Omya (UK), respectively. The particle size distribution of all solid powders used in this study was measured using a particle characterisation instrument (Morphologi G3, Malvern Instruments) and is shown in Fig. 4.

PC, clinker and alite were also characterised using an X-ray diffractometer (PANalytical X'Pert Pro) with a $\mathrm{Cu} \mathrm{K}_{\alpha}$ radiation source. The X-ray diffraction (XRD) patterns are shown in Fig. 5 and were recorded over $2 \theta$ ranging from $20^{\circ}$ to $70^{\circ}$ and step size of $0.033^{\circ}$ with the $\mathrm{X}$-ray tube operated at $40 \mathrm{kV}$ with $40 \mathrm{~mA}$. The XRD patterns of $\mathrm{PC}$ and clinker contain all the peaks observed in the alite pattern. This is consistent with the fact that the former two are mostly composed of alite. However, there are a few peaks in PC and clinker patterns which cannot be found in alite. These are highlighted in Fig. 5. Due to the complexity and overlapping of diffraction peaks associated with different minerals in clinker and PC, no attempt was made to identify these peaks and quantify the minerals. However, the XRD patterns confirm that the composition of these materials are different. According to the data provided by the supplier, the clinker (which was also used in PC) has the following mineralogical composition: $40-60 \%$ alite, $12.5-30 \%$ belite, $7-12 \%$ aluminate, and $6-10 \%$ ferrite. 


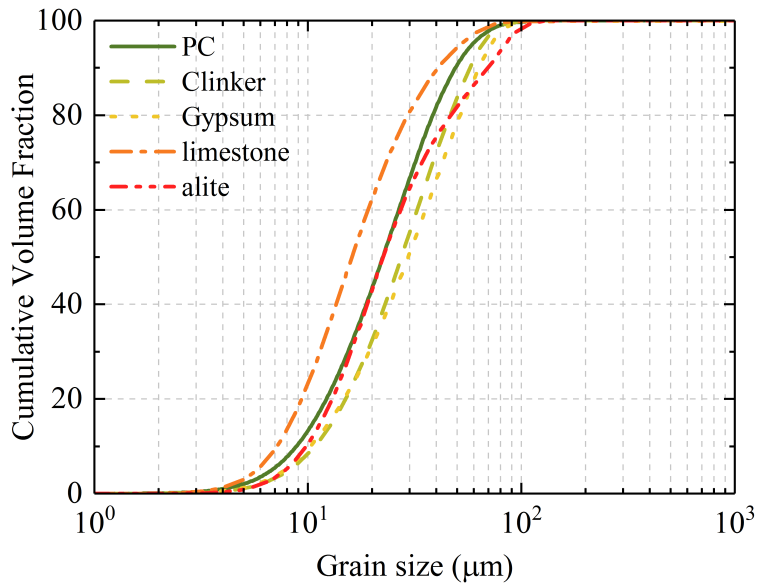

Fig. 4: Particle size distribution of all inorganic materials used in this study. All materials have a similar fineness except limestone which is slightly finer compared to other materials.

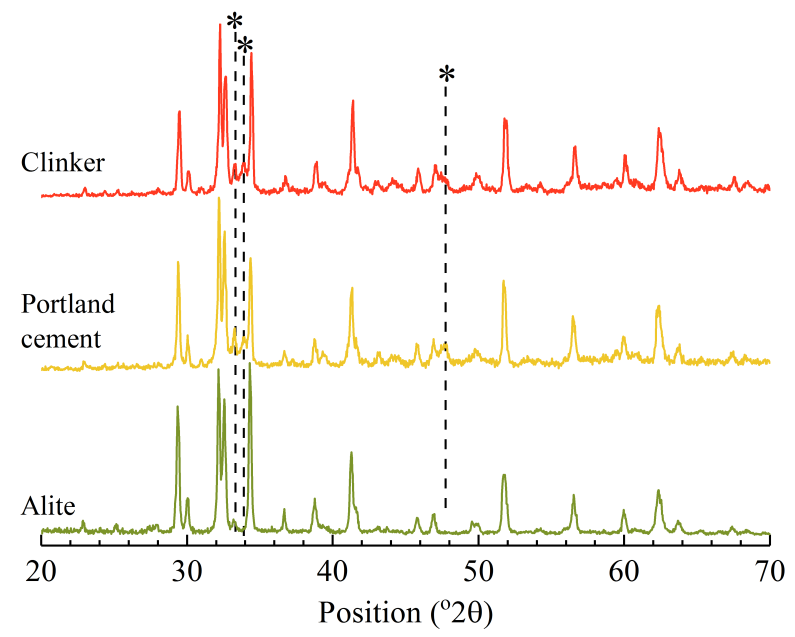

Fig. 5: X-ray powder diffraction pattern of PC, clinker and synthetic alite. Peaks highlighted with dashed lines show the differences between PC and clinker patterns with that of alite. The difference arises from the presence of phases other than alite in clinker and PC, for instance belite and aluminate.

\subsection{Iso-thermal calorimetry}

An isothermal calorimeter (TAM Air model, TA instruments) was used to measure the hydration heat of cement pastes. The instrument is highly accurate with a detection limit of $4 \mu \mathrm{W}$ and baseline drift of less than $40 \mu \mathrm{W}$ over two weeks. All calorimetry tests were conducted at $20{ }^{\circ} \mathrm{C}$ and in three replicates 
unless otherwise stated.

Pastes were prepared by mixing $4 \mathrm{~g}$ of solid powder with deionised water which either contained GO or not. PC and alite were only used alone, but clinker was either used alone or partly substituted with gypsum or limestone. In some cases, alite and $\mathrm{PC}$ pastes were prepared in the presence of a $\mathrm{PCE}$ copolymer (Viscocrete10, Sika). For these samples, the GO colloids were first prepared using the procedure outlined before. The copolymer was then added to the colloids and stirred by a magnetic stirrer for 30 seconds. The total water to solid mass ratio varied, but this was always fixed to either $0.4,0.5$ or 0.6. After the initial contact of the solids with water, the mixture was stirred at a speed of $400 \mathrm{rpm}$ for 2 minutes in a plastic vial using an overhead stirrer (RW 20, IKA). Thereafter, the vial was sealed tightly and placed into the calorimeter. For each sample, the whole preparation process up to the initial point of measurement required about 3 minutes. The first hour of the calorimetry data was discarded in all experiments. This ensured that the measured heat only corresponded to the hydration reactions, and that the pastes were at the equilibrium with the calorimeter.

\subsection{Compressive strength tests}

The compressive strength of the pastes was determined at 7, 14 and 28 days of hydration. Strength tests were preformed using a servo-hydraulic machine (Advabtest 9, Controls group) with a maximum capacity of $300 \mathrm{kN}$ and a loading platen made of hardened steel. PC and clinker were the only hydraulic materials used in this experiment. Water-to-solid ratio was fixed to 0.4 for all pastes.

Specimens were $25 \mathrm{~mm}$ cubes. Each cube was prepared and cast individually by mixing $21.7 \mathrm{gr}$ of $\mathrm{PC}$ or clinker powder with $8.7 \mathrm{~mL}$ of aqueous solution (with or without GO). This led to pastes with a desired volume to fit a $25 \mathrm{~mm}$ cube. Our mixing process is somewhat unusual. The reason for mixing cubes individually was to ensure that each specimen contains a fixed amount of GO. Unfortunately, this could not be achieved using the standard mixing methods such as ASTM-C109 [44], as GO aggregates while mixing the pastes [5]. This 
resulted in a highly scattered strength data as shown in Fig. 6. The large scatter observed for standard mixing was due to the fact that aggregated GO was not dispersed homogeneously amongst different samples during casting; that is each cube contained a different quantity of GO. To avoid this, samples were mixed individually which resulted in a lower scatter (Fig. 6).

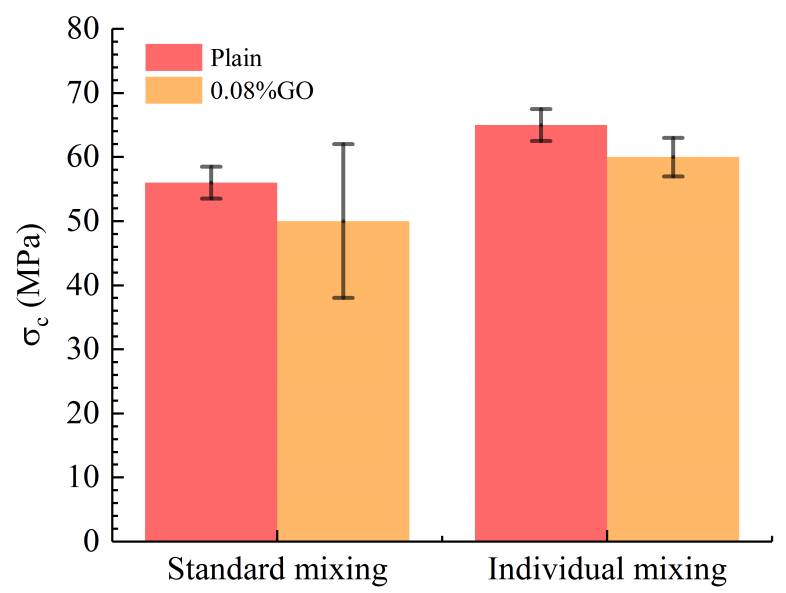

Fig. 6: Compressive strength of $\mathrm{PC}$ paste containing $0.08 \% \mathrm{GO}$ (added with respect to $\mathrm{PC}$ mass) at 28 days of hydration, indicating the effect of mixing method. Standard mixing refers to the results obtained following ASTM-C109 [44], but individual mixing is for samples prepared individually using overhead stirrer. Data were obtained by testing 10 cubes $(25 \mathrm{~mm})$, and the error bars show the whole variation in strength data but exclude the faulty samples according to ASTM-C109.

Pastes were mixed in a small plastic container using the IKA overhead stirrer at a speed of $2000 \mathrm{rpm}$ and for a period of 3 minutes. The volume of paste for each cube was sufficiently small so that the stirrer could provide an appropriate mixing condition. Thereafter, each paste was cast into moulds that had three compartments. After casting, each mould was subjected to vibration for 30 seconds. Immediately after, moulds were carefully covered with a plastic foil and were then placed in the moist room for 24 hours. After this time, the samples were placed in a plastic container filled with saturated lime water until they were tested for compressive strength.

The total maximum load indicated by the testing machine was recorded for each specimen, and the corresponding compressive strength was calculated ac- 
cording to ASTM-C109 [44]. Samples were loaded at a rate of $1200 \mathrm{~N} / \mathrm{s}$. For each cube, dimensions of the surfaces subjected to the loading was measured and used for the strength calculation. Strength data obtained for each batch of specimens were averaged and reported along with their variation. Faulty specimens (as defined in ASTM-C109 [44]) were excluded from strength calculations. One sample per 10 cubes was usually found faulty. The coefficient of variation varied depending on the sample, but this was found to be less than $7 \%$ after excluding faulty data, which satisfies the requirements stated in ASTM-C109 standard.

\subsection{Scanning Electron Microscopy (SEM)}

A SEM microscope (JEOL JSM-6480LV) in back-scattered electron (BSE) mode was used to study hydrated alite pastes containing the PCE copolymer. The primary aim was to investigate whether GO has a seeding effect during hydration; that is whether GO causes precipitates to grow on the gain surfaces as well as in the paste pore space. Samples selected for the SEM analysis were first studied in the calorimeter. To do this, PCE was first added to a GO colloid (the amount of PCE and GO depended on the mix design). This was then mixed with alite powder by hand in the calorimetry vial for 30 seconds. Once the caloirmetry test was completed, pastes were removed from the instrument and further cured at $20^{\circ} \mathrm{C}$. The total curing time for each sample was 14 days, including the period of calorimetry experiment. When the desired time had elapsed, the hydration was ceased by drying the pastes in a freeze-drier for 8 hours with no pre-freezing. It is known that freeze-drying can be damaging to microstructural features in the paste, however as this part of the study only aims to locate the regions where hydrates were formed, the drying method makes no significant difference to the conclusions. Dried samples were impregnated with an epoxy resin (EPO-SET, Metprep) under vacuum conditions, and left in a plastic mould for 24 hours to set at room temperature. The resin-impregnated specimens were gently ground using different grades of abrasive papers (silicon carbide, Metprep) and then polished with diamond pastes (Metprep) down to 
$1 \mu \mathrm{m}$. Finally, the polished surfaces were coated with gold and used for the SEM-BSE imaging.

\section{Results and Discussion}

\subsection{Effect of $G O$ on the hydration of clinker}

Fig. 7 shows the rate of heat evolution for the hydration of clinker in the absence or presence of various quantities of GO. GO reduces the rate of heat flow during the acceleration period, and it delays the time at which the maximum heat flow occurs. However, the value of maximum heat flow remains almost the same in all samples. From these observations, it is evident that GO has a retarding effect on clinker hydration, and that the extent of this effect depends on the amount of GO added in the pastes.

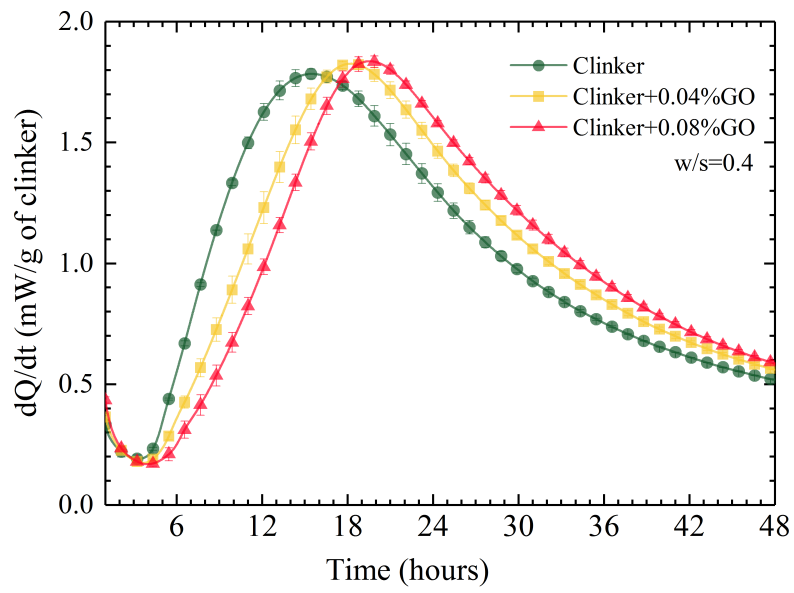

Fig. 7: Rate of heat evolution of clinker hydration in the absence and presence of GO, measured for pastes with water-to-clinker ratio of 0.4 . The data was normalised with respect to clinker mass and error bars show the whole range of heat flow at different hydration times, calculated for three replicates.

To assess the reproducibility of the retardation observed for clinker-GO pastes, the calorimetry tests were repeated three times for each of the mixes shown in Fig. 7. It was found that the extent of retardation varied widely, and this led us to repeat the calorimetry tests 20 times - each time the hydration of one plain clinker paste was only compared to that of a paste containing $0.08 \%$ 
of GO. The time and level of heat flow at the peak, denoted $t_{p}$ and $H_{p}$ respectively, were read from each heat evolution curve. Fig. 8 shows how the addition of GO changes $t_{p}$ and $H_{p}$ for clinker pastes. For comparison, this figure also shows the effect of GO on the heat evolution curve of alite hydration, based on the data reported in [5]. In agreement with Fig. 7, Fig. 8 confirms that GO has little effect on the maximum value of heat flow in clinker pastes. However, GO delays the time of the peak although this change is very variable, ranging from 1 to 10 hours. In spite of this variability, Fig. 8 clearly shows that retardation is the only significant effect on clinker hydration. By contrast, the addition of GO in alite paste only induced acceleration during hydration, with much less scatter. In alite pastes, GO increases the level of heat flow at the peak and slightly accelerates the time of maximum heat flow.

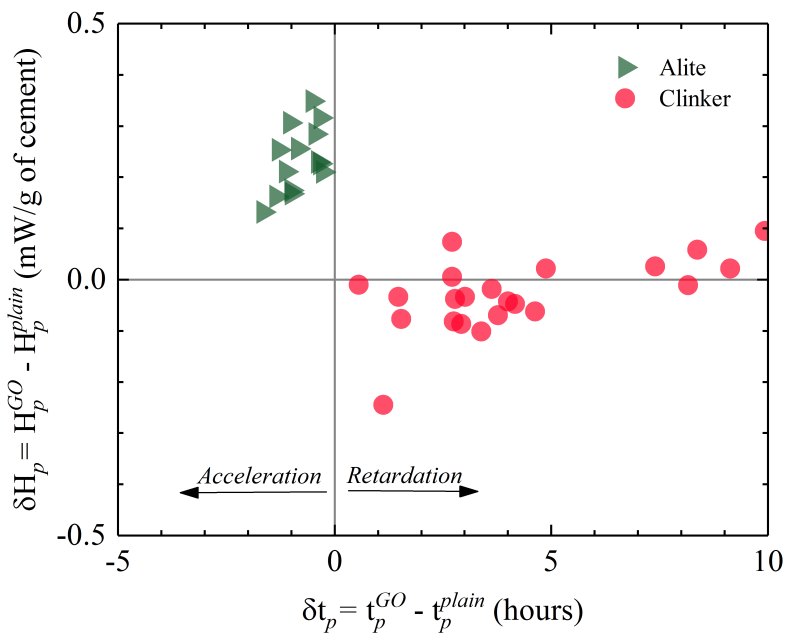

Fig. 8: The extent to which the addition of GO in clinker pastes alters the position of time and heat flow at the peak of calorimetry curve (denoted $t_{p}$ and $H_{p}$ resp.). Each dot corresponds to an independent experiment, and shows the difference observed for $t_{p}$ and $H_{p}$ between a plain paste and that containing $0.08 \%$ GO. All clinker data are for pastes with a water-to-solid ratio of 0.4. Alite data are for pastes with various water-to-solid ratio (inc. 0.4), based on calorimetry tests reported in [5].

To examine the longer-term effect of GO on the kinetics of clinker hydration, Fig. 9 shows the cumulative heat evolution of clinker pastes measured for 90 hours, in the absence and presence of GO. The patterns reveal that the slow- 
down in clinker hydration only happens temporarily (between 12 to 24 hours for the samples shown in this figure), after which the total heat recorded for pastes with GO becomes higher than that of plain paste. This is more visible in Fig. 9 for clinker pastes containing $0.08 \%$ GO. This observation demonstrates that GO affects clinker hydration in two different ways: it initially retards the hydration, but eventually accelerates it. Each curve shown in Fig. 9 is the average of the heat data obtained from three samples made of the same paste. A similar retarding/accelerating behaviour was observed when the experiment was repeated but the data shown in Fig. 9 was chosen for presentation because the retardation is one of the longest.

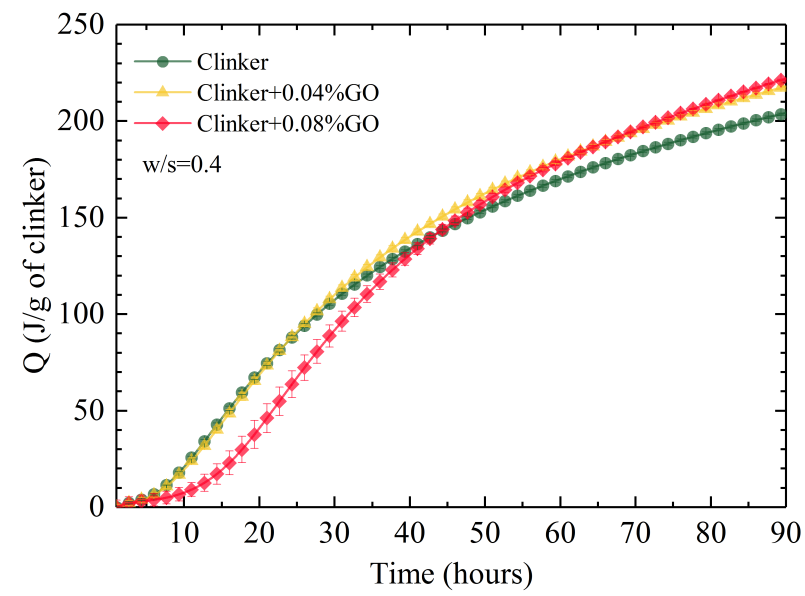

Fig. 9: The cumulative heat evolution of clinker hydration with and without the addition of GO, measured for pastes with water-to-solid ratio of 0.4 . The heat data correspond to the average of three replicates, and the error bars show the whole range of heat calculated for three pastes. GO temporarily retards the clinker hydration.

The observations in Fig. 7 and Fig. 8 are unusual and surprising, particularly in light of previous reports where GO was found to accelerate alite [5] and PC $[20,25,26,38]$ hydration. To our knowledge, this is the first time that GO has been found to act as a retarder during a chemical reaction involving dissolution and precipitation. The usual expectation is that adding GO in cement pastes should only accelerate cement hydration [7]. This is because GO (even if only present in aggregated form $[5,25,26])$ serves as an extra surface for the growth 
of hydration precipitates $[9,10,12,14,16]$, which increases the rate of precipitation and drives the overall rate of hydration reactions towards acceleration [5]. However, results shown in Fig. 8 do not follow this pattern, indicating that GO acts differently during clinker hydration compared to alite and PC.

The reason(s) why GO retards clinker hydration is not straightforward to identify, but we herein propose a number of hypotheses. The process of clinker hydration consists of a series of complex dissolution and precipitation reactions, all of which initiate at the liquid-solid interface. If GO delays the hydration, it must somehow hinders these dissolution and/or precipitation reactions. This could occur if:

1. GO directly reduces the rate of dissolution by binding to the active dissolution sites on the surface of clinker grains; that is the retardation is a dissolution-controlled phenomenon at the surface of hydrating grains.

2. GO limits the nucleation and growth of hydration precipitates, either by reducing the bulk concentration of dissolved ions required to form the nuclei of hydrates or by preventing the diffusion of ions at the liquid-solid interface. The former is a process controlled within the bulk pore solution whereas the latter occurs in the diffusion layer on the grain surfaces.

The first mechanism is highly unlikely. During the first few days of hydration, alite and aluminate $\left(\mathrm{C}_{3} \mathrm{~A}\right.$ doped by alkali metals) phases are by far the most reactive minerals in clinker grains [45]. The overall rate of heat evolution $\left(\frac{d Q}{d t}\right)$ in Fig. 7 is the superposition of the heat released or used by the hydration reactions, as described by Eq. 1:

$$
\frac{d Q}{d t}(t)=\sum_{i=1}^{n} \frac{d \alpha_{i}}{d t} \Delta H_{i}(t)+\sum_{j=1}^{m} \frac{d \beta_{j}}{d t} \Delta H_{j}(t)
$$

where $\Delta H_{i}$ is the dissolution enthalpy of cement phase $i$ (amongst $n$ phases), and $\Delta H_{j}$ is the enthalpy of the formation of hydration products $j$ (amongst $m$ phases). $\frac{d \alpha_{i}}{d t}$ is the rate by which phase $i$ dissolves in water, and $\frac{d \beta_{j}}{d t}$ is the rate by which hydration product $j$ forms. In general, the dissolution of alite and 
aluminate phases in water is an exothermic process and the major contributor to the net heat flow of clinker hydration $[45,46]$, whereas the precipitation of hydration products are mostly endothermic except for the formation of calcium aluminate hydrates which are exothermic [45, 47, 48]. From Fig. 7, it appears that GO simply retards the whole hydration of clinker without changing the overall shape of the calorimetry curve. We know from Fig. 8 that GO does not retard the dissolution of alite, therefore it follows that GO should have retarded the dissolution of aluminate. If GO selectively retarded the dissolution of aluminate, the resulting hydration curves would either show separate peaks or a drop in the maximum heat flow, according to Eq. 1. Although some of the clinker data in Fig. 8 show a small reduction in the value of maximum heat flow, this is not the dominant effect and the hydration curves never show separated peaks. Therefore, it seems reasonable to infer that the effect of GO on clinker hydration is not dissolution-controlled, and that the origin of retardation involves the hydration of both alite and aluminate phases.

It is accepted that the nucleation and growth of precipitates is the ratecontrolling step during the acceleration period in calorimtery curves [49-51]. This implies that the lower the rate of precipitation, the lower the slope of the calorimetry curve during the acceleration period. It is clear from Fig. 7 that GO reduces this slope, and this reinforces the conclusion that GO delays the precipitation reactions and not the dissolution of the clinker grains.

The precipitation reactions can be retarded in two ways. The first is that GO remains in the paste pore solution and forms complex with cations (e.g. calcium). Evidence exists that GO contains about $1.6-3.7 \mathrm{mmol} / \mathrm{g}$ of carboxylate sites in its molecular structure [5]. Complexation of GO with calcium could drop the calcium concentration in the bulk pore solution. This could then prevent the ionic composition required to reach the supersaturation level of precipitates (e.g. C-(A)-S-H), thereby delaying both the formation of initial nuclei as well as the subsequent growth of hydrates. If this occurred, a similar behaviour would be expected to take place when GO is added in alite paste [52]. However, alite hydration is not retarded, as shown in Fig. 8; therefore, it can be inferred 
that retardation is not controlled by a process occurring within the pore solution either.

The only remaining possibility is that GO affects the nucleation of hydrates from within the diffusion layer close to the surface of clinker grains. At the clinker surface, GO may delay the diffusion of ions released from the dissolution of clinker, thereby delaying the time required for ions to come together and form the first nuclei of hydrates. This hypothesis does not necessarily imply that GO acts as a physical barrier for the diffusion of ions. It may only temporarily affect the ionic concentration at the liquid-solid interface, possibly by complexation with calcium.

The exact reactions involved are difficult to determine and the precise role of GO on clinker surfaces remains unclear. Since GO has no retarding effect on alite hydration [5], it is plausible that other crystallites in clinker, such as aluminate phase, controls the attraction of GO to the clinker grains. Additional calorimetry experiments to characterise the interaction of GO with these phases could be helpful, but this is beyond the scope of this study. A possible contributing factor to the surface interaction could be the carboxylated group of GO. Carboxyl sites, which deprotonate in alkaline solutions, allow GO layers to acquire a negative electrostatic charge, causing them to adsorb onto the clinker surfaces with positive charges $[5,32]$. However, it is not straightforward to identify exactly which minerals (cement phases and hydration products) could provide such positive charges. It has been reported that the zeta-potential of $\mathrm{C}_{3} \mathrm{~A}$ particles is positive in water, whereas $\mathrm{C}_{3} \mathrm{~S}$ is negatively charged $[34,53]$. However, there seems to be no general agreement on the charge characteristics of these phases, as some suggest that both $\mathrm{C}_{3} \mathrm{~S}$ and $\mathrm{C}_{3} \mathrm{~A}$ are positively charged in aqueous suspensions [35]. In any case, zeta-potential only provides the net charge in a system, and since cement particles are quite reactive in water, it is extremely difficult to separate the charge of the grain surfaces from that of the ions in the pore solution or the hydration products.

The scatter of the data shown in Fig. 8 and the retarding-accelerating effect observed in Fig. 9 could be due to the complexities involved in the interaction 
of GO with clinker surfaces. It is possible that GO has a mixed accelerating and retarding effect in the paste, depending on whether it is in the pore solution or at the clinker surface. In the former case, it could provide extra surface for the growth of hydrates, which would accelerate hydration. In the latter case, it would hinder hydration. This mixed behaviour is quite probable as the surface of clinker grains are heterogeneous in charge density and mineralogical composition $[34,35]$, so that some of the GO layers could remain in the pore solution while the rest binds to the clinker surface. The degree of GO aggregation in the paste pore solution as well as the distribution of the carboxyl sites around the edges of GO layers could be quite variable, which further contributes to the complexity of the observed phenomena.

It was also found that the dilution of the paste with water decreases the extent of retardation. Fig. 10 shows how GO affects the position of the peak in the calorimetric curves of clinker hydration, obtained for pastes with various water-to-clinker ratios. It can be seen that as the total aqueous volume increases, GO retards the hydration less. Some samples with water-to clinker ratio of 0.6 even show an accelerating effect. This indicates that the aqueous volume in clinker paste plays a determinant role in the extent to which GO retards clinker hydration. This may be because the distance between the clinker particles contributes to the GO retarding effect: the higher the distance between the particles, the lower the GO tendency to bind to clinker surfaces. If this were the case, some physical processes could control the retarding effect of GO. For instance, the shear between GO and cement particles during mixing could play a role. Another possible interpretation of the effect of water content is that, at low water-to-solid ratio, GO binds to an amorphous precipitate (with a size of couple of nanometers) on the clinker surfaces while mixing the paste. The binding of GO to this phase is responsible for the retardation. The aqueous volume plays an important role here, as it controls the supersaturation level of the paste pore solution with respect to this precipitate. As more water is included in the paste, the supersaturation degree reduces and so less precipitate forms; that is GO makes less interaction with the surface of hydrating grains. 

on hydration is highly variable.

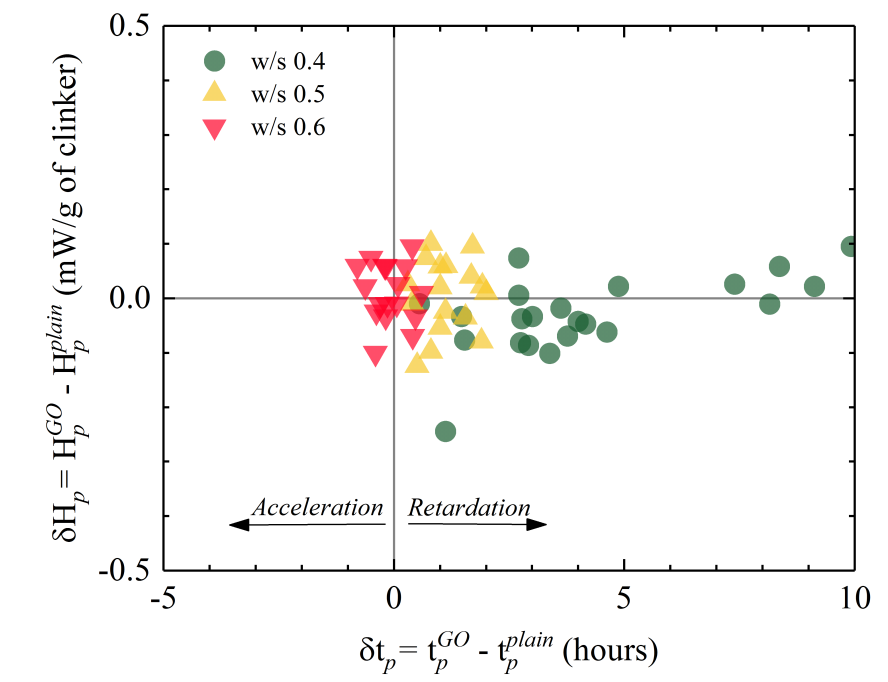

Fig. 10: Effect of water to clinker ratio $(\mathrm{w} / \mathrm{s})$ on the extent to which the presence of GO in clinker pastes alter the position of peak in calorimetry curves. The higher the aqueous volume, the lower the extent of clinker retardation.

However, it is difficult to investigate these processes directly as the GO effect

Effect of $G O$ on the hydration of $P C$

This section investigates the effect of GO on PC hydration. Fig. 11 shows the rate of heat evolution for the reaction of $\mathrm{PC}$ with water in the absence or presence of GO. All heat evolution curves are consistent with the typical trend of PC hydration, with only two significant heat flow maxima throughout the hydration (magnified for clarity in the inset in Fig. 11). The first peak is mostly related to the dissolution of alite as well as the precipitation of portlandite and C-(A) $-\mathrm{S}-\mathrm{H}$ phases, whereas the second peak is attributed to the dissolution of the aluminate phase and the precipitation of ettringite although alite hydration also contributes to this peak [45]. These calorimetry data show that GO increases the level of heat flow during the acceleration period as well as for the maximum value reached at the peak. The time of the maximum heat flow is almost unchanged. It can be observed from Fig. 11 that the effect of GO on the peak of alite reaction is different to that of the aluminate phase, the latter 
being more pronounced. We discuss the significance of alite reaction peak in this section while the aluminate reaction will be discussed in Section 3.3.

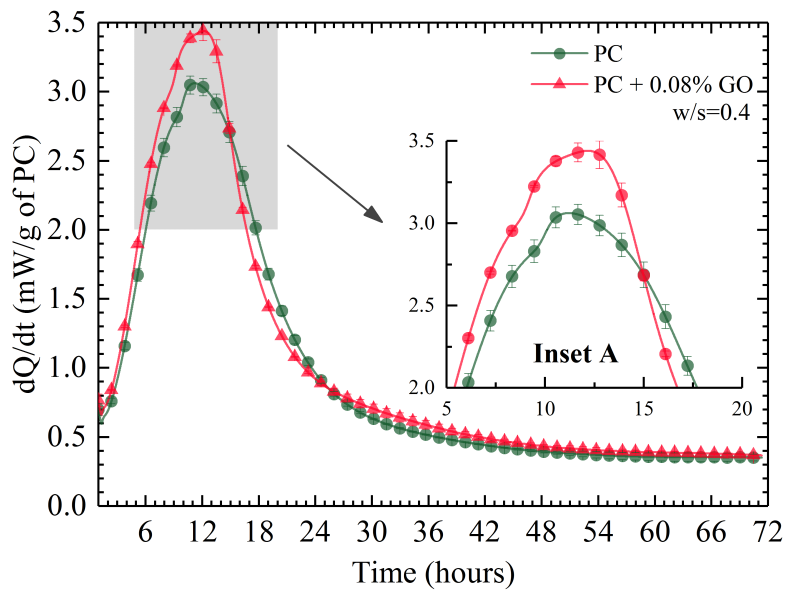

Fig. 11: Heat evolution patterns of PC hydration in the absence and presence of $0.08 \%$ GO (this ratio is with respect to $\mathrm{PC}$ mass), measured for pastes with water-to-solid ratio of 0.4 . Data shown here were averaged from three independent replicates, and error bars show the whole range of values.

The accelerating effect of GO observed in Fig. 11 for alite peak is consistent with previous reports [20, 25,38]. However, the extent of the effect observed here is barely significant and is similar to that observed for pure alite hydration [5]. Past studies proposed that GO provides a significant amount of surface area in PC pastes, and that this additional surface area is directly related to the degree of acceleration [20]. Hou et al. recently simulated the interface between GO (only containing hydroxyl group) and a tobermorite-like structure with and without the presence of aluminium $(\mathrm{C}-(\mathrm{A})-\mathrm{S}-\mathrm{H})$ [38]. They suggested that the GO/C-(A)-S-H interface has a hydrophilic nature, and that the GO surface is highly reactive, causing the nuclei of hydrates to easily form on its surface [38]. $\mathrm{Li}$ et al. also claimed that $\mathrm{C}-\mathrm{S}-\mathrm{H}$ forms on the GO "single" layers in dilute suspension, prepared from mixing sodium silicate and calcium nitrate with a $\mathrm{pH}$ maintained at 12 [54]. Therefore, there seems to be a general consensus that GO adds a significant amount of active surface area for nucleation in PC pastes. To better appreciate the GO effectiveness as a nucleation surface, Fig. 12 
compares how two solid additives, namely GO and quartz, affect the kinetics of PC hydration. Quartz was chosen for comparison because it is inert during PC hydration [55], and its effect on hydration is mainly physical, by providing extra surface for nucleation. In Fig. 12, the data for PC pastes mixed with quartz are reproduced from the two studies by Berodier and Scrivener [55] and Oey et al. [56]. For these data, the studies estimated that the presence of quartz particles increases the total surface area of the paste by about $0.1-0.3 \mathrm{~m}^{2}$ per gram of solid. On the other hand, if we assume that GO remains in the form of single layers as claimed formerly, then the total surface available for precipitations in PC pastes containing $0.08 \% \mathrm{GO}$ is about $1.6-1.8 \mathrm{~m}^{2}$ per gram of solid. This range was calculated considering that a GO single layer has a surface area of $1500-1700 \mathrm{~m}^{2} / \mathrm{g}$ [5], and PC used in this study has a BET surface area of 0.46 $\mathrm{m}^{2} / \mathrm{g}$. Overall, this means that GO would add to the paste an extra surface of about $1.2 \mathrm{~m}^{2} / \mathrm{g}$. It is clear from Fig. 12 that GO and quartz have a similar effect on PC hydration, implying that the contribution of GO as nucleation surface in PC-GO pastes is not commensurate with the amount of extra surface that GO single layers would provide. To put these results into perspective, Fig. 12 also shows two dots for pure alite hydration, based on the calorimetry data reported by Costoya [57]. These dots show that when the total surface area in alite paste is increased by 1 or $2 \mathrm{~m}^{2} / \mathrm{g}$ (by changing the powder fineness from $82 \mu \mathrm{m}$ to $18 \mu \mathrm{m}$ or $13 \mu \mathrm{m}$, resp.), the maximum heat flow also increases by 1 or $2 \mathrm{~mW} / \mathrm{g}$. If GO provided $1.2 \mathrm{~m}^{2} / \mathrm{g}$ of extra surface area, one would expect the change in hydration to be much more significant. Therefore, it is likely that GO does not remain in the single layer form in PC pastes, or if it does, its surface is not very active for nucleation. This conclusion is further confirmed in Section 3.6, where we show that GO could actually be a very active nucleation surface.

\subsection{Effect of $G O$ on hydration of clinker-gypsum or clinker-limestone}

GO retards clinker hydration but accelerates PC hydration. To help identify the factor(s) causing this difference, calorimetry experiments were conducted multiple times on samples where clinker was partially replaced by gypsum to 


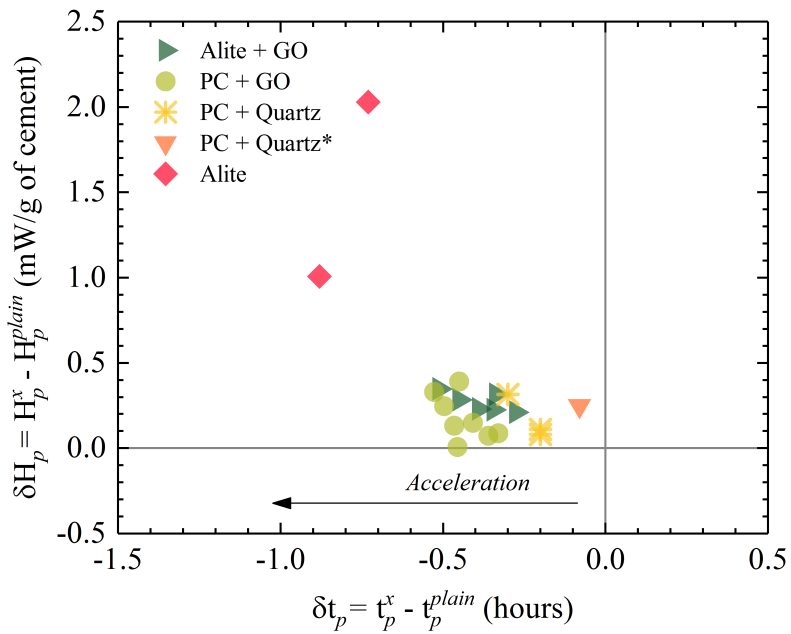

Fig. 12: Effect of GO and quartz on the heat evolution pattern of $\mathrm{PC}$ and alite hydration. Data for alite+ $\mathrm{GO}$ is from [5] for $0.08 \% \mathrm{GO}$ and water-to-solid ratio of 0.4. $\mathrm{PC}+\mathrm{GO}$ was obtained from multiple replicates in this study for the same water and GO content. PC+quartz and $\mathrm{PC}+$ quartz $^{*}$ were based on data reported in [56] and [55], respectively. $x$ refers to samples with solid additives. Data shown for alite is based on calorimetry tests reported by Costoya [57] for various alite fineness.

obtain pastes with compositions closer to PC. Two clinker-gypsum systems were produced: in one, clinker was substituted with $2.5 \%$ wt.\% gypsum, while in the other with $5 \%$ wt. $\%$ gypsum. The heat evolution patterns of these two clinkergypsum systems are shown in Fig. 13. In agreement with the data shown for PC hydration in Fig. 11, all clinker-gypsum samples undergo acceleration in the presence of GO. Therefore, the presence of gypsum counteracts the retarding effect of GO in clinker pastes. As the retardation in clinker-GO pastes was quite variable, calorimetry tests were also repeated multiple times both for PC and for gypsum-clinker systems. Fig. 14 shows the extent to which GO alters the position of the first peak. It can be observed that GO has an accelerating effect on both systems in all repeated measurements with much less scatter than that previously observed in clinker pastes.

It is well known that gypsum retards the hydration of the aluminate phase in clinker. This retardation was once attributed to the formation of a hydrate layer acting as a permeable barrier on the aluminate surface, thereby hindering 

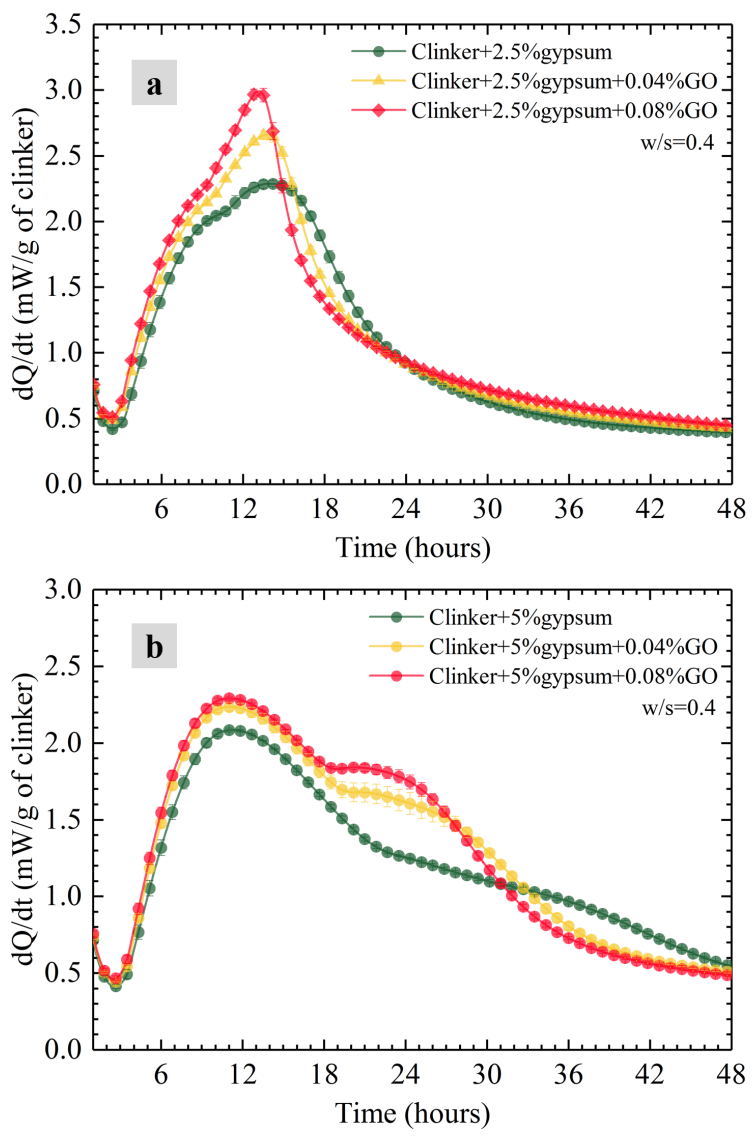

Fig. 13: Heat evolution curves of clinker-gypsum hydration with and without adding $0.04 \%$ and $0.08 \%$ GO (with respect to PC mass). Gypsum is used in substitution of clinker, and all pastes had a water-to-solid ratio of 0.4 .

the diffusion of ions and water molecules. This theory is now considered unlikely [51]. Minard et al. [58] proposed that the slowdown in $\mathrm{C}_{3} A$ hydration is caused by the adsorption of sulphate ions on the active dissolution sites in $\mathrm{C}_{3} A$, reducing the rate of dissolution. This happens because gypsum is highly soluble and quickly releases sulphate ions both in the solution and in the close vicinity of the aluminate surfaces. Similarly, when water (with or without GO) is added to the clinker-gypsum or PC systems, sulphate adsorbs onto the aluminate sites in clinker surfaces. Therefore, it is reasonable to conclude that it is the sulphate ions that counteract the clinker-GO retardation. Since sulphate adsorption oc- 


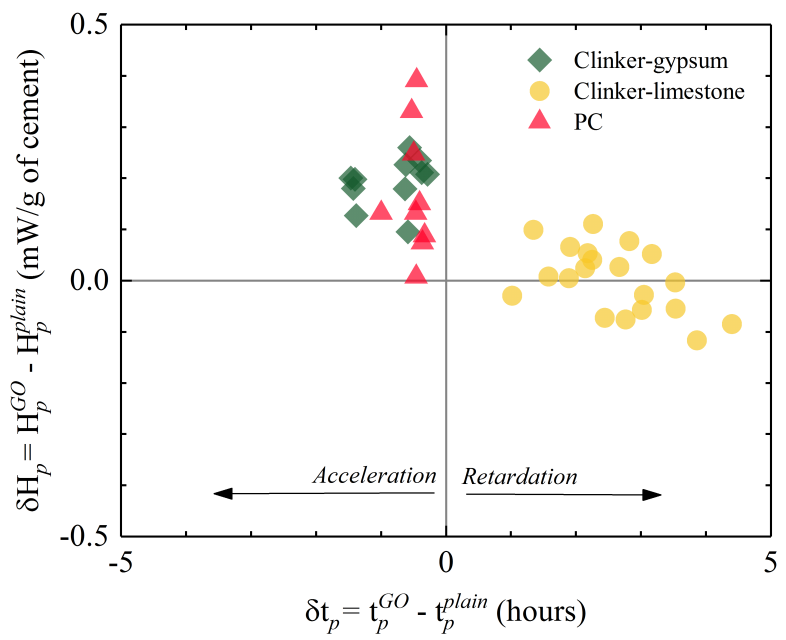

Fig. 14: Effect of GO on the change of maximum heat flow and the time at the peak rate, obtained from isothermal calorimetry tests for pastes made of either PC or clinker-substituted gypsum and limestone. All pastes had water-to-solid ratio of 0.4. Limestone and gypsum were used in $2.5 \%$ wt.\% substitution of clinker.

curs at the liquid-solid interface and it is the only possible change that could occur to clinker grains, our previous hypothesis that GO retards hydration via a surface-controlled process is further supported. Sulphate counteracts the retarding effect of GO as it alters the surface characteristics of clinker grains. This finding is also consistent with the sulphate-adsorption theory proposed in $[51,58]$ and to our knowledge, it is the first direct observation that sulphate changes the clinker surfaces while mixing the paste. Based on the hypotheses made in this study, sulphate changes the properties of the clinker grains in two ways: either it switches the charge of the $\mathrm{C}_{3} A$ surfaces from positive to negative, preventing GO from adsorption onto this phase; or it precludes the formation of the amorphous precipitate to which GO binds and retards the hydration.

Comparing Fig. 13 and Fig. 14 with Fig. 7, it appears that gypsum plays an important role in preventing GO from retarding clinker hydration. There are two characteristics of gypsum that are at play: its high solubility and its affinity with the aluminate phase. To confirm this, Fig. 14 also presents the effect of $\mathrm{GO}$ on clinker hydration in the presence of limestone. Unlike gypsum, limestone 
is significantly less soluble, and it has no retarding effect on the hydration of the alite or aluminate phases. It can be seen from Fig. 14 that GO retards clinker-limestone hydration in a similar way that it does clinker hydration.

GO affects the position of the aluminate shoulder in the hydration curves. From Fig. 11 and Fig. 13, GO significantly accelerates the hydration of the aluminate phase but has little effect on the first peak (alite). A similar behaviour has often been observed for PC pastes where cement is partially replaced by fillers such as quartz or limestone $[51,55,56,59]$. The exact reason behind the acceleration is controversial, but it has often been attributed to three possible mechanisms. In the first one, the filler dilutes the paste thereby increasing the total water to cement ratio, thus providing more water, which in turn causes more hydration $[46,51]$. According to the second mechanism, the filler provides extra surface area for the nucleation of hydrates [59]. As more hydration products form, the reactions tend to accelerate. The third mechanism, suggested by Quennoz and Scrivener [46], states that $\mathrm{C}-(\mathrm{A})-\mathrm{S}-\mathrm{H}$ gel formed during alite hydration takes up sulphate ions, which limits the extent to which sulphate retards aluminate dissolution. Based on the data shown in Fig. 13, pastes were neither diluted nor did GO provide any significant amount of surface for the formation of hydrates [5]. It appears that GO behaves in a way which is consistent with the third mechanism. Further quantitative analyses are necessary for a detailed understanding of this mechanism, but it could occur as follows. A number of simultaneous reactions take place before the second peak in Fig. 13: alite dissolves to form $\mathrm{C}-(\mathrm{A})-\mathrm{S}-\mathrm{H}$ and $\mathrm{Ca}(\mathrm{OH})_{2}$, and $\mathrm{C}_{3} A$ and gypsum dissolve to form ettringite $[45,46]$. During these processes, the $\mathrm{C}-(\mathrm{A})-\mathrm{S}-\mathrm{H}$ gel removes sulphate from the paste pore solution as it forms. This prevents sulphate from interacting with $\mathrm{C}_{3} A$ surfaces, resulting in the hydration of this phase being less retarded. Once gypsum is fully dissolved (i.e. there is no supply of sulphate from gypsum), some of the ettringite precipitates become unstable and dissolve into the paste solution, generating sulphate ions. In addition to this, sulphate also desorbs from the $\mathrm{C}-(\mathrm{A})-\mathrm{S}-\mathrm{H}$ gel and participates in a reaction with $\mathrm{C}_{3} A$ to form monosulphoaluminate $[46,51]$. This reaction would cause the second peak 
in Fig. 13. It is also expected that ettringite continues to form in this system after the second peak, unlike pure $\mathrm{C}_{3} A$-gypsum systems where ettringite fully dissolves and converts to monosulphate [60]. Overall, the acceleration observed in the calorimetry data could have simply resulted from the increasing formation of $\mathrm{C}-(\mathrm{A})-\mathrm{S}-\mathrm{H}$ onto which sulphate ions absorb.

\subsection{Dominant role of GO in PC paste}

Previous reports suggested that GO adsorbs onto the surface of PC particles while mixing the paste [33], as also discussed in the introduction. However, based on the results shown in Sections 3.1-3.3, if GO interacts with the surface of hydrating particles, one should clearly expect a delay in hydration. Given that retardation does not occur during PC-GO hydration, the surface interaction suggested in previous studies seems unlikely. The key phase that prevents GO from interacting with the surface of PC particles is gypsum. Therefore, the dominant behaviour of GO in $\mathrm{PC}$ pastes is that it aggregates in the pore solution of paste (away from the surfaces of PC particles), and serves for the nucleation and growth of hydration precipitates although the extent of this effect is small.

\subsection{Strengthening mechanism of graphene oxide in cement paste}

According to previous reports, GO improves the mechanical properties of hydrated cement pastes. However, the strength data are often reported as a function of time. This makes it difficult to differentiate the main factor contributing to the strength improvements. In this section, we report the compressive strengths as a function of hydration heat (as a proxy for hydration degree) for PC and clinker pastes containing various amounts of GO. This allows us to assess the strength improvements as hydration advances over time.

Fig. 15 shows the total heat of hydration measured for PC and clinker pastes using isothermal calorimetry. The dominant effect of GO is that it increases the extent of PC and clinker hydrations. We used the value of heat at 7, 14 and 28 days of hydration to prepare Fig. 16, where the strength of either PC (Fig. 16a) or clinker pastes (Fig. 16b) is presented as a function of total heat. Strength 
tests were conducted on $25 \mathrm{~mm}$ cubes according to the method described in Section 2.4. Pastes for calorimetry were prepared following the same method used for the cubes, including the time and speed of mixing. The only difference is that pastes for strength tests were cured in saturated lime aqueous solution after 24 hours while calorimetry pastes were not exposed to extra water at all. These two systems are different in how they harden over time. Samples hydrated in lime-water develop more strength compared to calorimetry pastes, so the strength and hydration data shown in Fig. 16 are not directly correlated to each other for a single sample. However, changes of heat and strength for a GO-containing paste can be compared in relative terms to the plain paste.

Fig. 16a shows the strength-heat data for hardened PC pastes. For plain samples, it can be seen that strength increases as hydration proceeds. Lines were fitted to the data to show the trend in the strength-heat data. Two types of behaviour can be observed from Fig. 16a or b, depending on the concentration of GO. At low GO concentrations (0.02\% and $0.04 \%)$, the strength increases in some cases by as much as $\sim 5 \mathrm{MPa}$, but this seems to be correlated to the change in the hydration heat. Comparing plain and GO-containing samples, there is no evidence that GO increases strength more than it enhances hydration. However, at higher GO concentration (0.08\%), strength degrades and is clearly less well correlated to the change in hydration (compared to the plain pastes). Although samples with GO hydrates faster than plain pastes, this trend does not follow that of strength development. A similar behaviour can also be observed for clinker pastes, as shown in Fig. 16b. The strength degradation is probably because GO introduces defects in the paste matrix, by causing a poor connectivity between the hydration products.

From our data, GO either slightly increases the compressive strength of PC and clinker pastes, or degrades it. Given that the GO strengthening follows the change in the degree of hydration heat (as shown for both PC and clinker), it is reasonable to suggest that GO improves the strength only by increasing the hydration degree. If GO had reinforced the paste or improved any microstructural features (as claimed in previous reports $[7,9-11,15,17,18,20,25,26]$ ) in 

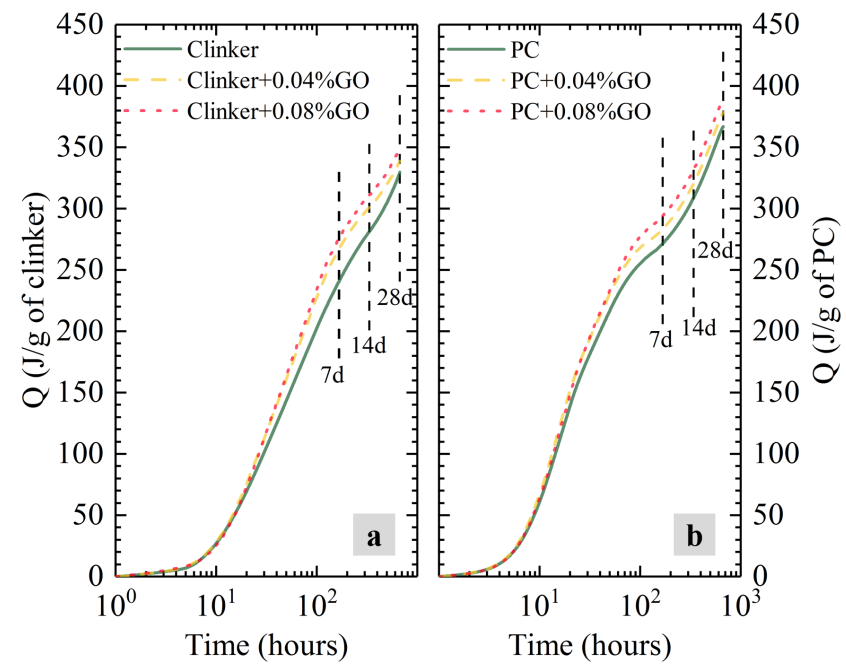

Fig. 15: Total heat of hydration as a function of time (hours), measured using isothermal calorimetry. Data are for (a) clinker and (b) PC pastes over 28 days of hydration at $20{ }^{\circ} \mathrm{C}$. Samples contained $0,0.02 \%, 0.04 \%$ or $0.08 \%$ GO. Patterns for pastes with $0.02 \%$ GO was very close to the plain paste and is not shown in this figure.

any substantial way, then one would expect the strength to advance much more than hydration, but this is not observed here.

\subsection{Effect of GO-PCE on alite and $P C$ hydration}

It has often been stated that PCE copolymer prevents GO from aggregation both in $\mathrm{Ca}(\mathrm{OH})_{2}$ electrolytes as well as in PC pastes $[23,24,39,40]$. This section investigates the validity of this claim for pastes with water-to-solid ratios of 0.4 . We examine the extent to which PCE-stabilised GO affects the kinetics of alite and PC hydration. Based on the results shown in Section 3.2, GO aggregates in PC paste pore solution while mixing the paste and it behaves as an almost inert material. This occurs as GO loses the majority of its oxygen-based functional groups in the alkaline environment of the paste, and it transforms into a much less hydrophilic material [5]. This makes GO a fairly ineffective nucleation surface in the paste (similar to quartz), with only a slight accelerating effect on the hydration kinetics. To test whether PCE disperses GO in cement pastes and alters its behaviour, GO colloids containing different amounts of PCE copolymer 

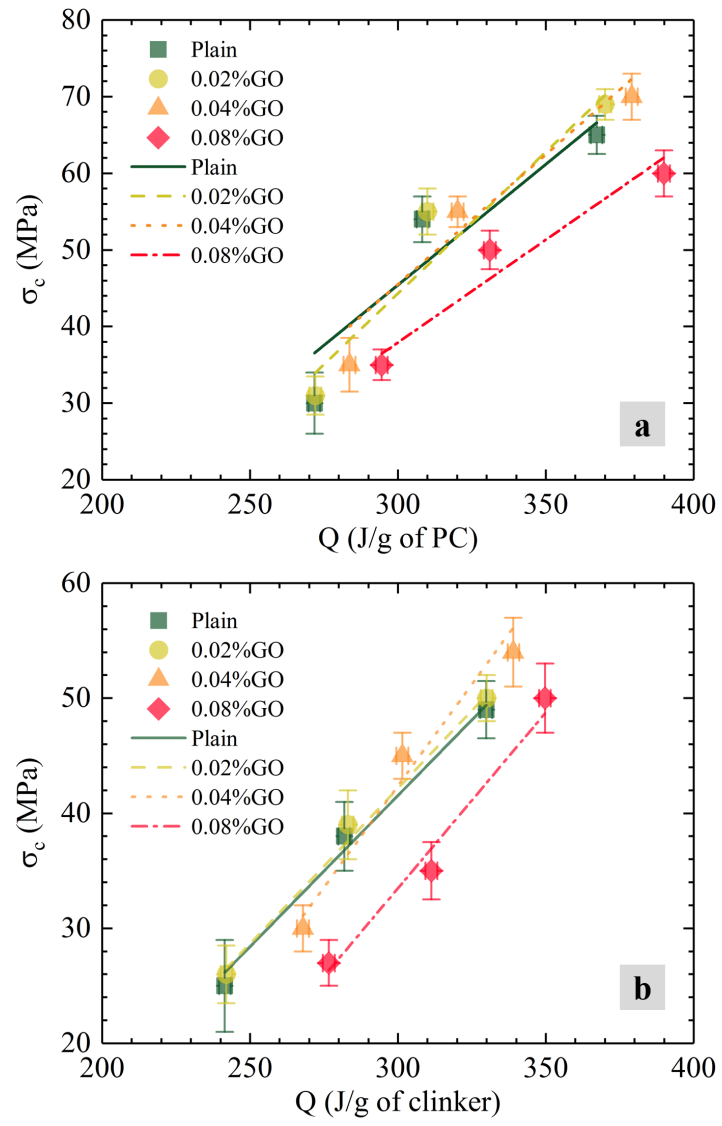

Fig. 16: Compressive strengths as function of total hydration heat. Data are for (a) PC and (b) clinker. The error bars show two times standard deviation. Lines are linear fits to the data. Data points are for 7 (the lowest values), 14 and 28 (the highest values) days. Both heat as well as strength are the increasing function of time.

were used to prepare pastes made of either alite or PC binders. Control samples were pastes without GO but with PCE. The heat released from these pastes was monitored using isothermal calorimetry.

Fig. 17 shows the degree of alite hydration, $\alpha$ (solid lines), and the rate of heat flow, $d Q / d t$ (dashed lines), as functions of time, acquired from calorimetry tests for various alite-PCE-GO pastes. $\alpha$ was estimated by dividing the total heat of hydration at each time step by the enthalpy of alite hydration which is $517 \mathrm{~J} / \mathrm{g}$ [47]. All ratios shown in Fig. 17 are with respect to alite mass. 

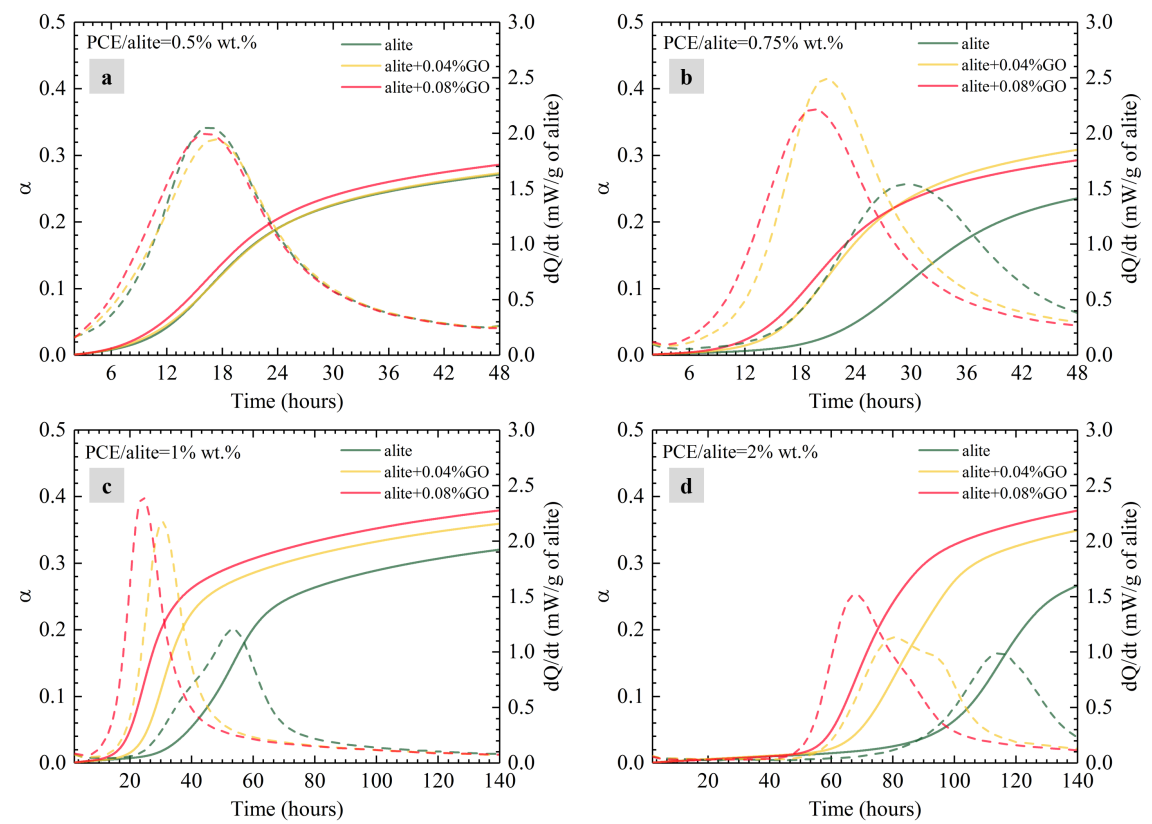

Fig. 17: Effect of GO on the pattern of alite hydration measured for various alite-PCE systems with: (a) $20 \mathrm{mg}(0.5 \%$ wt.\%), (b) $30 \mathrm{mg}$ (0.75\% wt.\%), (c) $40 \mathrm{mg}$ (1\% wt.\%), (d) $80 \mathrm{mg}$ (2\% wt.\%) PCE included in the paste. The wt.\% values correspond to PCE:alite mass ratio. Water to alite mass ratio was fixed to 0.4 . Two GO colloids with concentrations of $1 \mathrm{mg} / \mathrm{mL}$ and 2 $\mathrm{mg} / \mathrm{mL}$ were used to prepare the pastes, which resulted in samples with GO:alite mass ratio of either $0.04 \%$ or $0.08 \%$ wt.\%. Note that the data in (a) and (b) are shown for 48 hours when the main hydration peak occurs, whereas (c) and (d) show the calorimetry pattern for 140 hours. Dashed lines show the rate of heat evolution, whereas the solid lines show the degree of hydration $(\alpha)$.

Fig. 17a shows the hydration of alite paste containing $0.5 \% \mathrm{PCE}$, with or without the presence of $0.04 \%$ and $0.08 \%$ wt.\% GO. All calorimetry patterns are almost the same, and GO has no particular effect on hydration. This observation is similar to that made from the calorimetry data reported for alite-GO systems without PCE in [5], where GO aggregated in the paste and made little contribution as a nucleation surface to the hydration. Fig. 17b shows the hydration of alite-GO paste containing $0.75 \%$ PCE. In this case, GO has an accelerating effect on hydration. At a given time of hydration, the alite-PCE pastes containing GO are at a higher degree of hydration compared to the plain paste. GO also increases the rate of heat evolution during the acceleration period, and it short- 
ens the induction period. However, there is no significant difference between the pastes containing $0.04 \%$ and $0.08 \%$ GO. Finally, Fig. 17c and Fig. 17d show that GO accelerates alite hydration in pastes with $1 \%$ and $2 \%$ PCE. In these systems, the effect of various GO concentrations can be clearly distinguished. Overall, PCE copolymer retards alite hydration. This behaviour was expected, as PCE acts as a retarder during cement hydration [34, 45, 61, 62]. As more PCE is added to the paste, the hydration is retarded more (Figs. 17a-d). However, GO reduces the extent of the retardation in some cases (e.g. Figs. 17b-d): at low PCE:GO ratio, GO is not active during hydration, whereas at higher PCE:GO ratio, it accelerates the hydration.

The key finding is that PCE retards alite hydration but GO could mitigate it to some extent. This reveals the rate-controlling step for PCE-alite hydration, which has already been the subject of some controversy [34, 45, 61, 62]. There are three competing theories on how PCE molecules retard alite hydration: they either (i) form complexes with $\mathrm{Ca}^{2+}$ ions in the paste pore solution $[34,62]$, or (ii) adsorb onto the nuclei of hydration products and/or the surface of anhydrous grains $[34,45]$, or (iii) prevent the diffusion of ions at the cement-solution interface [34]. These phenomena mainly control the rate of two processes during hydration; alite dissolution, or the nucleation and growth of hydration products. One way to find the rate-controlling process is to add seeds (usually C-S-H) to alite/cement pastes [49]. If seeds increase the rate of hydration, the rate-controlling step seems to be the nucleation and growth process [49]. If they do not accelerate the hydration, the rate-controlling process is dissolution [63]. In the case of the data in Fig. 17, GO behaves in a similar way to $\mathrm{C}-\mathrm{S}-\mathrm{H}$ seeds. GO accelerates alite-PCE hydration because it serves for the nucleation of precipitates and encourages the formation of hydration products [5], which PCE would otherwise hinder. Therefore, it seems likely that PCE limits the nucleation and growth process and not the dissolution. At least, this should be the case for most of the hydration, but it is also possible that the rate-controlling step switches from dissolution to nucleation during the induction period. This twofold behaviour is quite plausible for cement hydration in 
the presence of additives [63].

Fig. 18 shows the BSE-SEM micrographs of hydrated alite pastes containing $2 \%$ PCE with and without the addition of $0.08 \%$ GO. These samples were hydrated for 14 days and then impregnated with resin. The micrograph in Fig. 18a indicates that in the absence of GO, the hydration precipitates formed primarily around the alite particles. The dark-black regions in Fig. 18a indicates the pore space in the paste. The alite-PCE system containing GO has a completely different micrograph, as shown in Fig. 18b. It can be seen that the formation of hydration products is not limited to the surface of alite particles. GO layers seem to be dispersed in the pore solution of the paste, away from the surface of the alite particles, where they served for the nucleation and growth of hydrates. The black pore spaces clearly visible in Fig. 18a are no longer obvious in Fig. 18b. This is because GO encourages the formation of hydrates in the presence of PCE, and as a result, precipitation is not limited to the alite surfaces in Fig. 18b.

The above observation also indicates that GO can become an active nucleation surface during alite hydration but only if a sufficient amount of PCE is present in the paste. We propose that this behaviour happens because PCE prevents GO from aggregating in the paste. It is also likely that PCE preserves the majority of the GO functional groups in the paste solution, making the GO surfaces active for the formation of the hydrates nuclei. The extent to which PCE prevents the GO aggregation depends on its quantity in the paste. In a way, this finding also supports the hypothesis proposed in [5] and in Section 3.2 that GO aggregates in the paste, causing little effect on alite and PC hydration.

Unlike alite systems, the effectiveness of PCE at dispersing GO in PC pastes is markedly different. Calorimetry tests were conducted on PC pastes with various PCE concentrations $(0.5 \%, 1 \%, 2 \%, 5 \%$ wt.\%). The effect of GO on the position of the main peak in the calorimetry curves is presented in Fig. 19. For comparison, results for alite-PCE pastes are also shown in this figure. PCE causes GO to significantly accelerate alite hydration. In some cases, the time of the calorimetry peak occurs 45 hours earlier. However, it seems that GO 

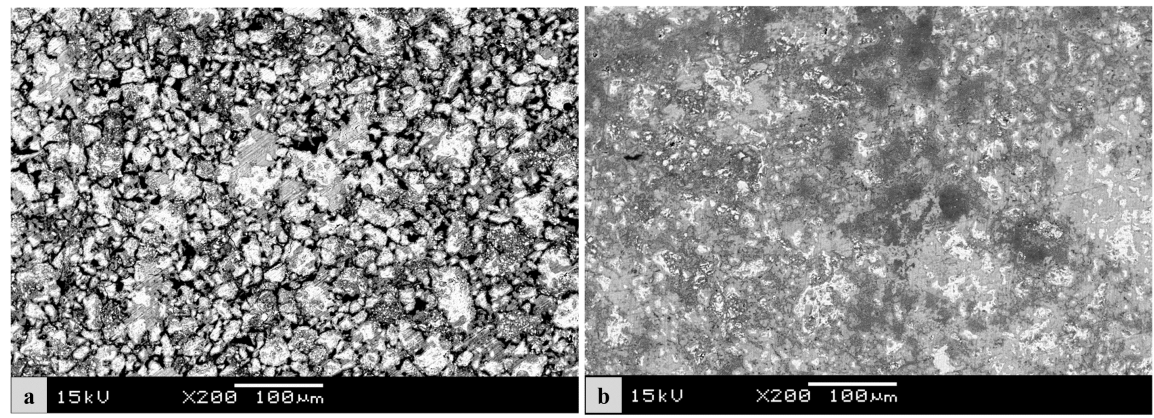

Fig. 18: BSE-SEM micrograph of hydrated alite paste containing $80 \mathrm{mg}$ PCE (2\% wt.\% of alite mass) mixed with $1.6 \mathrm{~mL}$ aqueous solution of (a) plain de-ionised water and (b) 2 $\mathrm{mg} / \mathrm{mL}$ GO (0.08\% wt.\% of alite mass). Both pastes had a water to alite mass ratio of 0.4 and hydrated for 14 days. Note that white and gray areas correspond to the alite particles and hydration products, respectively. The black regions which is more evident in (a), is related to the areas impregnated with epoxy resin, i.e. the pore regions in the actual paste.

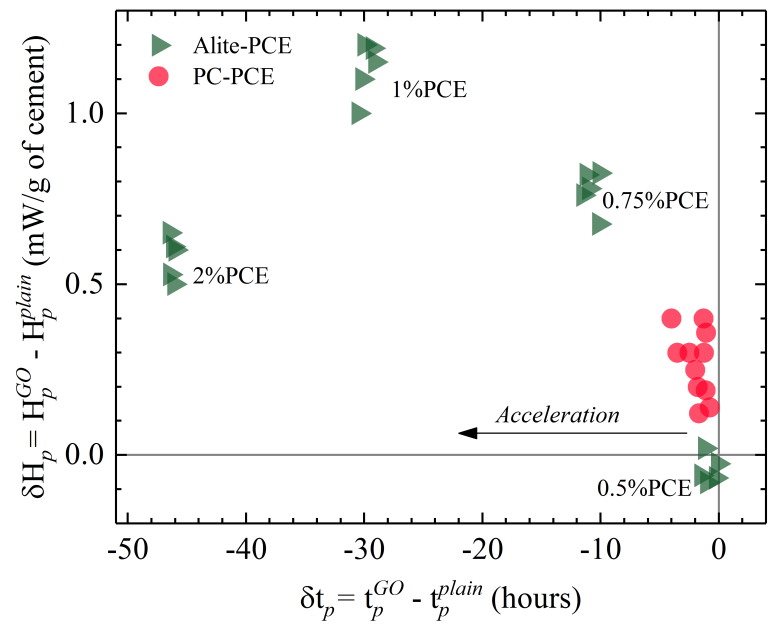

Fig. 19: Effect of $0.08 \%$ GO on the change of maximum heat flow and the time at the peak rate, obtained for alite and $\mathrm{PC}$ pastes. All pastes had water-to-solid ratio of 0.4 . PCE ratios are clearly tagged for alite pastes. Data shown for PC pastes were obtained with the addition of $0.5 \%, 1 \%, 2 \%$ and $5 \%$ wt. $\%$ PCE; however as the calorimetry patterns showed no significant difference, only a cluster of points are presented.

has no particular effect on PC-PCE hydration. As an example, Fig. 20 shows the hydration of PC in the presence of $5 \%$ PCE and $0.08 \%$ GO. GO has little effect on the position of the main peak, and it makes almost no change to the rate of heat flow during the acceleration period. This behaviour is similar to 


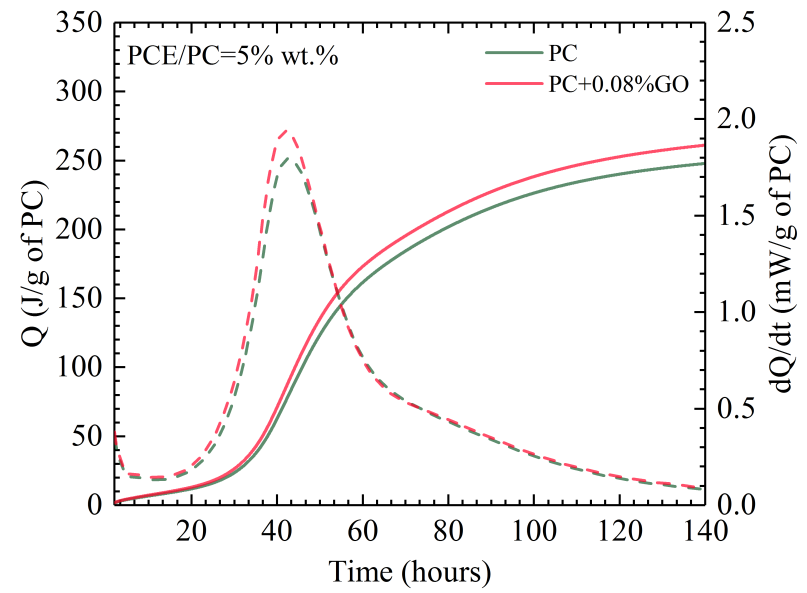

Fig. 20: Effect of $0.08 \%$ wt. $\%$ GO on the pattern of PC hydration, in the presence of $5 \%$ wt. $\%$ PCE copolymer. All pastes had water-to-solid ratio of 0.4. Dashed lines show the rate of heat evolution $(\mathrm{dQ} / \mathrm{dt})$, whereas the solid lines show the total heat $(\mathrm{Q})$.

the hydration of alite-GO without PCE [5] and is reminiscent of Fig. 17a where $\mathrm{PCE}$ is ineffective at dispersing GO. Overall, these findings confirm that PCE hardly prevents GO from aggregating in PC pastes, as it acts rather differently in PC paste compared to alite systems in Figs. 17b-d. This also implies that the strength improvements reported in previous studies [23, 24, 39, 40] resulted from the presence of GO aggregates rather than well-dispersed GO, as these studies only used $1 \%$ and $2 \%$ of PCE to mix GO with PC pastes.

We hypothesise that the difference in PCE effectiveness between PC and alite systems lies in the reactivity of these two binders, the complexity of their pore solution, and how PCE interacts with the surface of the hydrating particles as well as the hydration products. To appreciate why PCE is ineffective in PC paste, we herein outline the principle by which PCE prevents GO from aggregation in $\mathrm{Ca}(\mathrm{OH})_{2}$ electrolytes. Based on the mechanisms explained in the introduction and in [5], PCE essentially precludes GO from participating in two chemical reactions: (i) calcium complexation with the carboxyl sites in GO; (ii) the reaction of hydroxide ions with non-carboxyl functional groups in GO. PCE does these because: 
- It contains acidic sites with a high tendency to form complex with calcium [62]. The acidic carboxyl radicals in PCE react with $\mathrm{Ca}^{2+}$. This reaction seems to be thermodynamically favourable compared to GO-Ca ${ }^{2+}$ complexation, which minimises the extent to which calcium interacts with GO.

- It prevents the reaction of hydroxide ions with GO. PCE supplies $\mathrm{H}^{+}$ dissociated from its carboxyl $(\mathrm{COOH})$ sites, forming water together with $\mathrm{OH}^{-}$.

In alite paste, the system is rather simple and the pore solution of the paste mainly contains calcium, hydroxide and silicate ions. When water containing PCE and GO is mixed with alite particles, GO mostly remains in the pore solution [5], whereas some PCE adsorbs on alite surfaces and some remains in the solution $[34,61]$. In the solution, PCE competes with GO for reacting with calcium and hydroxide. As long as there exists a sufficient amount of PCE in the solution, GO remains dispersed. The effect of PCE-to-GO ratio is clear from Fig. 17.

Unlike alite, PCE is ineffective in PC paste, mainly because: (i) when PC is mixed with water, more than one phase immediately dissolves, enriching the pore solution with various divalent and trivalent cations; (ii) most of the PCE adsorbs on the surface cement grains, and/or it intercalates in some of the hydration products. It is highly likely that PCE immediately reaches its complexation capacity in PC paste due to the high ionic strength of the paste solution. At that point, GO is exposed to cations and hydroxide ions, forming clusters. It is possible that the majority of PCE molecules are removed from the pore solution while they are mixed with PC in the paste, as PCE tend to adsorb onto the surface of aluminate phase $[34,61]$. PCE could also co-precipitate with $\mathrm{C}-\mathrm{S}-\mathrm{H}$ and ettringite while mixing the paste $[64,65]$, being removed from the paste solution. All of these would limit the role of PCE in the paste solution as anti-coagulant. 


\section{Conclusions}

Hydration of PC and clinker pastes was studied in the absence and presence of GO, using a series of isothermal calorimetry experiments. GO retarded clinker hydration but accelerated PC hydration. We proposed that the retardation was due to the interaction of GO with the surface of hydrating clinker particles, which temporarily hindered the formation of precipitates nuclei. The exact cause for the attraction of GO to clinker surface remains unclear, but phases other than alite are key to understanding this behaviour. We suggested that aluminate phase could play a major role, but this needs to be investigated in future studies. Our results also show that the presence of gypsum in PC prevented GO from being a retarder during hydration. Since gypsum is soluble, we propose the sulphate ions released from gypsum dissolution immediately altered the surface characteristics of clinker particles which prevented GO from interacting with the grain surfaces.

Compressive strength tests were performed on paste cubes made of either $\mathrm{PC}$ or clinker. Strength data were reported as a function of hydration heat which was measured using isothermal calorimeter. Results indicated that GO enhanced the strength of PC and clinker pastes when the GO content was low (e.g. $0.02 \%$ or $0.04 \%$ ). However, the extent of this strength improvement was small ( $\sim 5 \mathrm{MPa})$ and seemed correlated to the change in the hydration heat. We found no evidence that GO improves strength more than it enhances hydration. This could imply that the reinforcing effect formerly assumed for the role of GO in cement pastes is not substantial.

Finally, this study revisited the claims from previous reports that PCE copolymer prevents GO from aggregation in PC pastes. Various GO-PCE colloids were prepared, each with a different PCE/GO ratio. They were used to prepare pastes made of either alite or PC. GO significantly accelerated the kinetics of alite-PCE hydration. In this case, PCE allowed GO to become an active seed for the nucleation and growth of hydration precipitates. This was because PCE reduced the extent to which GO aggregates in the pore solution 
of alite paste. On the other hand, PCE was found to be ineffective in preventing GO from aggregation in PC pastes. This is mostly because PCE tend to adsorb on cement grains or co-precipitate with some of the hydration products, all of which remove PCE from the paste pore solution and make it difficult to prevent GO from clustering. This also suggests that the strength improvements reported for PC-GO-PCE systems in previous reports were not caused by the presence of well-dispersed GO, and that the strengths were increased only due to the change in the hydration degree.

\section{Acknowledgments}

The financial support provided by the University College London (UCL) to the first author is gratefully acknowledged. The authors would like to thank Mrs Ainur Toksanbayeva for helping with the calorimetry tests; Mr Don McDonald from Quinn building products for supplying clinker and Portland cement; $\mathrm{Mr}$ Matthew Billing for his assistance with the synthesis of graphene oxide; $\mathrm{Mr}$ Tobias P. Neville for access to his muffle furnace; Mr Warren Gaynor and Dr Shi Shi and Dr Judith Zhou for their technical support throughout this study.

\section{References}

[1] D.R. Dreyer, S. Park, C.W. Bielawski, and R.S. Ruoff. The chemistry of graphene oxide. Chem. Soc. Rev., 39:228-240, 2010.

[2] J.H. Warner. Graphene: Fundamentals and emergent applications. Elsevier, London, first edition, 2013.

[3] L. Liu, J. Zhang, J. Zhao, and F. Liu. Mechanical properties of graphene oxide. Nanoscale, 4:5910-5916, 2012.

[4] J.W. Suk, R.D. Piner, J. An, and R.S. Ruoff. Mechanical properties of monolayer graphene oxide. ACS Nano, 4(11):6557-6564, 2010. 
[5] S. Ghazizadeh, P. Duffour, N.T. Skipper, M. Billing, and Y. Bai. An investigation into the colloidal stability of graphene oxide nano-layers in alite paste. Cem. Concr. Res., 99:116-128, 2017.

[6] T. Szabo, E. Tombacz, E. Illes, and I. Dekany. Enhanced acidity and pHdependent surface charge characterization of successively oxidized graphite oxides. Carbon, 44:537-545, 2006.

[7] S. Chuah, Z. Pan, J.G. Sanjayan, C.M. Wang, and W. H. Duan. Nano reinforced cement and concrete composites and new perspective from graphene oxide. Constr. Build. Mater., 73:113-124, 2014.

[8] H. Yang, H. Cui, W. Tang, Z. Li, N. Han, and F. Xing. A critical review on research progress of graphene/cement based composites. Composites: Part A, 102:273-296, 2017.

[9] S. Lv, Y. Ma, C. Qiu, T. Sun, J. Liu, and Q. Zhou. Effect of graphene oxide nanosheets of microstructure and mechanical properties of cement composites. Constr. Build. Mater., 49:121-127, 2013.

[10] S. Lv, J. Liu, T. Sun, Y. Ma, and Q. Zhou. Effect of GO nanosheets on shapes of cement hydration crystals and their formation process. Constr. Build. Mater., 64:231-239, 2014.

[11] Z. Pan, L. He, L. Qiu, A. Habibnejad Korayema, G. Li, J.W. Zhu, F. Collins, D. Li, W.H. Duan, and M.C. Wang. Mechanical properties and microstructure of a graphene oxide-cement composite. Cem. Concr. Compos., 58:140-147, 2015.

[12] Q. Liu, Q. Xu, Q. Yu, R. Gao, and T. Tong. Experimental investigation on mechanical and piezoresistive properties of cementitious materials containing graphene and graphene oxide nanoplatelets. Constr. Build. Mater., 127:565-576, 2016. 
[13] C. Lu, Z. Lu, Z. Li, and C.K.Y. Leung. Effect of graphene oxide on the mechanical behavior of strain hardening cementitious composites. Constr. Build. Mater., 120:457-464, 2016.

[14] M. Murugan, M. Santhanam, S.S. Gupta, T. Pradeep, and S.P. Shah. Influence of 2D rGO nanosheets on the properties of OPC paste. Cem. Concr. Compos., 70:48-59, 2016.

[15] S. Sharma and N.C. Kothiyal. Comparative effects of pristine and ballmilled graphene oxide on physico-chemical characteristics of cement mortar nanocomposites. Constr. Build. Mater., 115:256-268, 2016.

[16] T. Tong, Z. Fan, Q. Liu, S. Wang, S. Tan, and Q. Yu. Investigation of the effects of graphene and graphene oxide nanoplatelets on the microand macro-properties of cementitious materials. Constr. Build. Mater., 106:102-114, 2016.

[17] M. Wang, R. Wang, H. Yao, S. Farhan, S. Zheng, and C. Du. Study on the three dimensional mechanism of graphene oxide nanosheets modified cement. Constr. Build. Mater., 126:730-739, 2016.

[18] D. Kang, K.S. Seo, H.Y. Lee, and W. Chung. Experimental study on mechanical strength of GO-cement composites. Constr. Build. Mater., 131:303-308, 2017.

[19] M.M. Mokhtar, S.A. Abo-El-Enein, M.Y. Hassaan, M.S. Morsy, and M.H. Khalil. Mechanical performance, pore structure and micro-structural characteristics of graphene oxide nano platelets reinforced cement. Constr. Build. Mater., 138:333-339, 2017.

[20] W. Li, X. Li, S.J. Chen, Y.M. Liu, W.H. Duan, and S.P. Shah. Effects of graphene oxide on early-age hydration and electrical resistivity of portland cement paste. Constr. Build. Mater., 136:506-514, 2017.

[21] X.H. Zhu, X.J. Kang, K. Yang, and C.H. Yang. Effect of graphene oxide on the mechanical properties and the formation of layered double hydroxides 
(LDHs) in alkali-activated slag cement. Constr. Build. Mater., 132:290-295, 2017.

[22] Z. Lu, D. Hou, H. Ma, T. Fan, and Z. Li. Effects of graphene oxide on the properties and microstructures of the magnesium potassium phosphate cement paste. Constr. Build. Mater., 119:107-112, 2016.

[23] L. Zhao, X. Guo, C. Ge, Q. Li, L. Guo, X. Shu, and J. Liu. Investigation of the effectiveness of PC@GO on the reinforcement for cement composites. Constr. Build. Mater., 113:470-478, 2016.

[24] L. Zhao, X. Guo, C. Ge, Q. Li, L. Guo, X. Shu, and J. Liu. Mechanical behavior and toughening mechanism of polycarboxylate superplasticizer modified graphene oxide reinforced cement composites. Composites Part B: Engineering, 113:308-316, 2017.

[25] X. Li, Y.M. Liu, W.G. Li, C.Y. Li, J.G. Sanjayan, W.H. Duan, and Z. Li. Effects of graphene oxide agglomerates on workability, hydration, microstructure and compressive strength of cement paste. Constr. Build. Mater., 145:402-410, 2017.

[26] X. Li, Z. Lu, S. Chuah, W. Li, Y. Liu, W.H. Duan, and Z. Li. Effects of graphene oxide aggregates on hydration degree, sorptivity, and tensile splitting strength of cement paste. Composites: Part A, 100:1-8, 2017.

[27] K. Erickson, R. Erni, Z. Lee, N. Alem, W. Gannett, and A. Zettl. Determination of the local chemical structure of graphene oxide and reduced graphene oxide. Adv. Mater., 22:4467-4472, 2010.

[28] L. Wu, L. Liu, B. Gao, R. Munoz-Carpena, M. Zhang, H. Chen, Z. Zhou, and H. Wang. Aggregation kinetics of graphene oxides in aqueous solutions: Experiments, mechanisms, and modeling. Langmuir, 29:15174-15181, 2013.

[29] H. Wang and Y.H. Hu. Electrolyte-induced precipitation of graphene oxide in its aqueous solution. J. Colloid Interface Sci., 391:21-27, 2013. 
[30] X. Fan, W. Peng, Y. Li, X. Li, S. Wang, G. Zhang, and F. Zhang. Deoxygenation of exfoliated graphite oxide under alkaline conditions: a green route to graphene preparation. Adv. Mater., 20:4490-4493, 2008.

[31] A.M. Dimiev, L.B. Alemany, and J.M. Tour. Graphene oxide. origin of acidity, its instability in water, and a new dynamic structural model. ACS Nano, 7(1):576-588, 2013.

[32] C. Shih, S. Lin, R. Sharma, M.S. Strano, and D. Blankschtein. Understanding the $\mathrm{pH}$-dependent behavior of graphene oxide aqueous solutions: A comparative experimental and molecular dynamics simulation study. Langmuir, 28:235-241, 2012.

[33] M. Wang, R. Wang, H. Yao, Z. Wang, and S. Zheng. Adsorption characteristics of graphene oxide nanosheets on cement. RSC Advances, 6:6336563372, 2016.

[34] Y. Zhang and X. Kong. Correlations of the dispersing capability of NSF and PCE types of superplasticizer and their impacts on cement hydration with the adsorption in fresh cement pastes. Cem. Concr. Res., 69:1-9, 2015 .

[35] A. Zingg, F. Winnefeld, L. Holzer, J. Pakusch, S. Becker, and L. Gauckler. Adsorption of polyelectrolytes and its influence on the rheology, zeta potential, and microstructure of various cement and hydrate phases. $J$. Colloid Interface Sci., 323:301-312, 2008.

[36] G. Möschner, B. Lothenbach, R. Figi, and R. Kretzschmar. Influence of citric acid on the hydration of portland cement. Cem. Concr. Res., 39:275$282,2009$.

[37] C. Nalet and A. Nonat. Effects of functionality and stereochemistry of small organic molecules on the hydration of tricalcium silicate. Cem. Concr. Res., 87:97-104, 2016. 
[38] D. Hou, Z. Lu, X. Li, H. Ma, and Z. Li. Reactive molecular dynamics and experimental study of graphene-cement composites: Structure, dynamics and reinforcement mechanisms. Carbon, 115:188-208, 2017.

[39] Z. Lu, A. Hanif, C. Ning, H. Shao, R. Yin, and Z. Li. Steric stabilization of graphene oxide in alkaline cementitious solutions: Mechanical enhancement of cement composite. Mater. Des., 127:154-161, 2017.

[40] L. Zhao, X. Guo, Y. Liu, C. Ge, L. Guo, X. Shu, and J. Liu. Synergistic effects of silica nanoparticles/polycarboxylate superplasticizer modified graphene oxide on mechanical behavior and hydration process of cement composites. RSC advances, 7:16688-16702, 2017.

[41] D.C. Marcano, D.V. Kosynkin, J.M. Berlin, A. Sinitskii, Z. Sun, A. Slesarev, L.B. Alemany, W. Lu, and J.M. Tour. Improved synthesis of graphene oxide. ACS Nano, 4(8):4806-4814, 2010.

[42] Cement Part 1: composition, specification and conformity criteria for common cements. Standard, British Standards Institution, 2011.

[43] A. Wesselsky and O.M. Jensen. Synthesis of pure portland cement phases. Cem. Concr. Res., 39:973-980, 2009.

[44] ASTM C109/C109M-16a. Standard test method for compressive strength of hydraulic cement mortars (using 2-in. or [50-mm] cube specimens). Standard, American Society for Testing and Materials, West Conshohocken, PA, 2016.

[45] D. Jansen, J. Neubauer, F. Goetz-Neunhoeffer, R. Haerzschel, and W.D. Hergeth. Change in reaction kinetics of a portland cement caused by a superplasticizer - calculation of heat flow curves from xrd data. Cem. Concr. Res., 42:327-332, 2012.

[46] A. Quennoz and K.L. Scrivener. Interactions between alite and $\mathrm{C}_{3} \mathrm{~A}$ gypsum hydrations in model cements. Cem. Concr. Res., 44:46-54, 2013. 
[47] H.F.W. Taylor. Cement chemistry. Thomas Telford Publishing, London, second edition, 1997.

[48] S.A. Grant, G.E. Boitnott, C.J. Korhonen, and R.S. Sletten. Effect of temperature on hydration kinetics and polymerization of tricalcium silicate in stirred suspensions of CaO-saturated solutions. Cem. Concr. Res., 36:671-677, 2006.

[49] J.J. Thomas, H.M. Jennings, and J.J. Chen. Influence of nucleation seeding on the hydration mechanisms of tricalcium silicate and cement. J. Phys. Chem. C, 113(11):4327-4334, 2009.

[50] K.L. Scrivener and A. Nonat. Hydration of cementitious materials, present and future. Cem. Concr. Res., 41:651-665, 2011.

[51] K.L. Scrivener, P. Juilland, and P.J.M. Monteiro. Advances in understanding hydration of portland cement. Cem. Concr. Res., 78:3856, 2015.

[52] C. Nalet and A. Nonat. Effects of hexitols on the hydration of tricalcium silicate. Cem. Concr. Res., 91:87-96, 2017.

[53] K. Yoshioka, E. Tazawa, K. Kawai, and T. Enohat. Adsorption characteristics of superplasticizers on cement component minerals. Cem. Concr. Res., 32:1507-1513, 2002.

[54] H. Li, T. Du, H. Xiao, and Q. Zhang. Crystallization of calcium silicate hydrates on the surface of nanomaterials. J. Am. Ceram. Soc., pages 1-12, 2017.

[55] E. Berodier and K.L. Scrivener. Understanding the filler effect on the nucleation and growth of C-S-H. J. Am. Ceram. Soc., 97(12):3764-3773, 2014.

[56] T. Oey, A. Kumar, J.W. Bullard, N. Neithalath, and G. Sant. The filler effect: The influence of filler content and surface area on cementitious reaction rates. J. Am. Ceram. Soc., 96(6):1978-1990, 2013. 
[57] M. Costoya. Effect of particle size on the hydration kinetics and microstructural development of tricalcium silicate. PhD thesis, EPFL, 2008.

[58] H. Minard, S. Garrault, L. Regnaud, and A. Nonat. Mechanisms and parameters controlling the tricalcium aluminate reactivity in the presence of gypsum. Cem. Concr. Res., 37:1418-1426, 2007.

[59] S. Dittrich, J. Neubauer, and F. Goetz-Neunhoeffer. The influence of fly ash on the hydration of OPC within the first $44 \mathrm{~h}$-a quantitative in situ xrd and heat flow calorimetry study. Cem. Concr. Res., 56:129-138, 2014.

[60] A. Quennoz and K.L. Scrivener. Hydration of $\mathrm{C}_{3} \mathrm{~A}$-gypsum systems. Cem. Concr. Res., 42:1032-1041, 2012.

[61] Y. R. Zhang, X. M. Kong, Z. B. Lu, Z. C. Lu, and S. S. Hou. Effects of the charge characteristics of polycarboxylate superplasticizers on the adsorption and the retardation in cement pastes. Cem. Concr. Res., 67:184$196,2015$.

[62] T. Sowoidnich, T. Rachowski, C. Rößler, A. Völkel, and H. Ludwig. Calcium complexation and cluster formation as principal modes of action of polymers used as superplasticizer in cement systems. Cem. Concr. Res., 73:42-50, 2015.

[63] J.J. Thomas, S. Ghazizadeh, and E. Masoero. Kinetic mechanisms and activation energies for hydration of standard and highly reactive forms of $\beta$-dicalcium silicate $\left(\mathrm{C}_{2} \mathrm{~S}\right)$. Cem. Concr. Res., 100:322-328, 2017.

[64] M. Schönlein and J. Plank. Influence of PCE kind and dosage on ettringite crystallization performed under terrestrial and microgravity conditions. $J$. Am. Ceram. Soc., 00:1-10, 2018.

[65] M. Schönlein and J. Plank. A TEM study on the very early crystallization of C-S-H in the presence of polycarboxylate superplasticizers: Transformation from initial C-S-H globules to nanofoils. Cem. Concr. Res., 106:33-39, 2018. 